OPEN ACCESS

Edited by:

$P$. Vethamony,

Qatar University, Qatar

Reviewed by:

Priyadarsi D. Roy,

National Autonomous University of

Mexico, Mexico

Daria Litvinyuk,

A.O. Kovalevsky Institute of Biology of

the Southern Seas, Ukraine

${ }^{*}$ Correspondence:

Tadele Assefa Aragaw

taaaad82@gmail.com

Specialty section:

This article was submitted to

Toxicology, Pollution and the

Environment,

a section of the journal

Frontiers in Environmental Science

Received: 08 December 2021 Accepted: 13 January 2022

Published: 14 February 2022

Citation:

Mhiret Gela S and Aragaw TA (2022) Abundance and Characterization of Microplastics in Main Urban Ditches Across the Bahir Dar City, Ethiopia.

Front. Environ. Sci. 10:831417.

doi: 10.3389/fenvs.2022.831417

\section{Abundance and Characterization of Microplastics in Main Urban Ditches Across the Bahir Dar City, Ethiopia}

\author{
Sahlu Mhiret Gela ${ }^{1}$ and Tadele Assefa Aragaw ${ }^{2 *}$ \\ ${ }^{1}$ School Chemical and Mechanical Engineering, Woldia Institute of Technology, Woldia University, Woldia, Ethiopia, ${ }^{2}$ Faculty of \\ Chemical and Food Engineering, Bahir Dar Institute of Technology, Bahir Dar University, Bahir Dar, Ethiopia
}

Microplastics (MPs) pollution in water bodies, wastewater, and sewage is of concern due to their probable effects on the environment and human health. This study is a first-time attempt to evaluate MPs occurrence, abundance, characteristics, and polymeric types in sediment and agglomerated sewage water from several urban ditches in Bahir Dar, Ethiopia, in two class sizes ( $>0.5$ and $<0.5 \mathrm{~mm}$ ). Out of the total of $239 \mathrm{MP}$ particles, $61.09 \%$ were of $<0.5 \mathrm{~mm}$ and this dominant fraction was transparent and consisted of fragmentary shapes. The mean abundances of $<0.5 \mathrm{~mm}$ particles were $5 \pm 1.00$ items/ $50 \mathrm{~g}$ in sediment and $3.00 \pm 1.00 \mathrm{items} / \mathrm{ml}$ in agglomerated sewage water. Similarly, the abundances of $>0.5 \mathrm{~mm}$ fractions were $2.33 \pm 0.58$ items $/ 50 \mathrm{~g}$ in sediment and $1.33 \pm$ 0.58 items $/ 50 \mathrm{ml}$ in Agglomerated sewage water. Polyethylene (PE), Polypropylene (PP), polyethylene terephthalate (PET), Polystyrene (PS), polyamide (PA), and polyvinylchloride (PVC), were the most detected plastics. However, PET and PVC were not detected in the agglomerated sewage water samples.

Keywords: Bahir Dar city, urban ditch, water of agglomeration, sediments, microplastic, synthetic polymers

\section{HIGHLIGHTS}

- We studied microplastic pollution in an urban ditch in Bahir Dar city, Ethiopia.

- We demonstrate the pollution level of the sediment and water agglomeration sample.

- The highest abundance of MPs was recorded in sediments $=5 \pm 1.00 \mathrm{items} / 50 \mathrm{~g}$.

- For all sampling sites, fragments were the most abundant shape of MPs.

- Dominant polymers (PET, PE, PP, PS, PVC, and PA) were detected.

\section{INTRODUCTION}

Plastic pollution of the marine and the terrestrial environment, particularly in oceans and inland waters, has recently gained awareness as a global issue (Auta et al., 2017). The plastic production rate exponentially increases yearly, from 1.5 Mt in 1950 to $359 \mathrm{Mt}$ in 2019, most of which are single-use plastics (PlasticsEurope, 2019). Left unabated, world plastic waste would add up to 12 billion tons covering the globe by 2050 (Henry et al., 2019). With weathering from various environmental sources, macroplastics are subject to degradation, ultimately becoming microplastics (MPs) (< $5 \mathrm{~mm}$ ) which were first investigated and described in the 1970s (Carpenter and Smith, 1972; Carpenter et al., 1972). In terms of their origin, MPs can be grouped as primary MPs and secondary MPs. Primary MPs are small-sized industrially manufactured pellets, microbeads, and fragments 


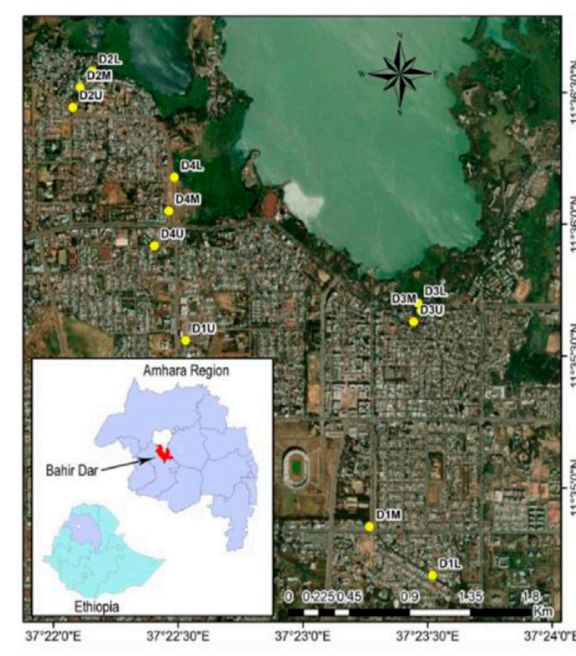

Map of the study area sampling
locations at each of the four major
ditches. Yellow dots indicates
sampling locations

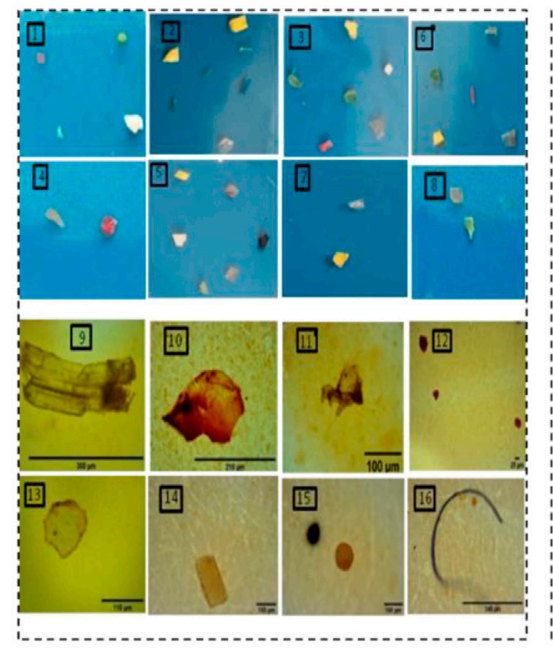

\begin{tabular}{|l|} 
Photographic (1-8) and \\
microscopic (9-16) representation \\
of identified MPs in different \\
sizes, shapes, and colors.
\end{tabular}

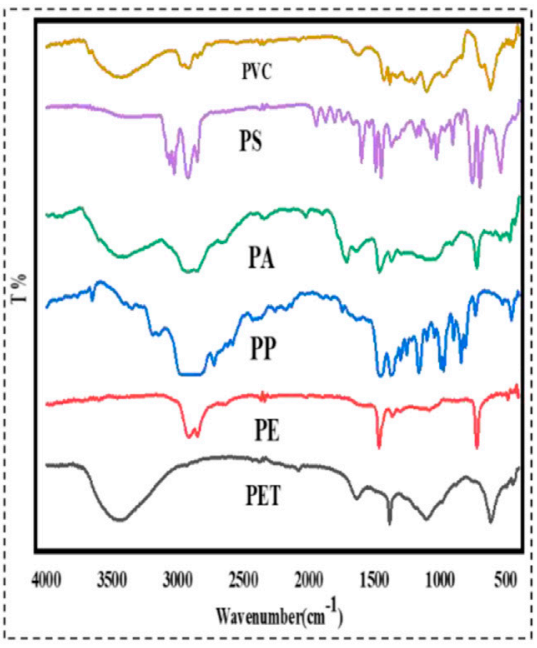

Identified polymer type of MPs both from sediment and water of agglomeration samples.

GRAPHICAL ABSTRACT |

(Auta et al., 2017), or else the product of industrial shot blasting processes wherein MPs are used as the abrasive media (Wagner and Lambert, 2018).

Secondary MPs form from the degradation and fragmentation of macroplastic through environmental weathering after being disposal (Wagner and Lambert, 2018). They may be fragments formed from the plastic litter on land and found in aquatic environments, and films produced from agrochemical use (Directive, 2013). Secondary MPs may also be fibers from fabrics produced from laundry as a result of everyday usage or cleaning and released from textile factories (Huppertsberg and Knepper, 2018). Microplastics and their degraded MPs and/or primary MPs enters into the freshwater as well as the marine environment if they are not properly managed, thus reaching the oceans (Lebreton et al., 2017) transported by rivers and other inland waters (Campos da Rocha et al., 2021). Moreover, large amounts of such emerging pollutants have an ecotoxicological effect on the aquatic biota, posing risks of fouling/entanglement, injury, and ingestion (Aragaw and Mekonnen, 2021b).

The occurrence and abundance of MPs in water, sediment, and biota have been tested and explored in a portion of the African nations (Alimi et al., 2021; Aragaw, 2021b). For Ethiopia, only one reported case study, Lake Ziway, was investigated regarding MP occurrence in fish and sediment (Merga et al., 2020). However, evidence about the occurrence and pollution level of MPs in Ethiopian lakes, rivers, estuaries, and other bodies of water is still scarce. To consider the solution of MPs pollution requires an ability to study their the occurrence and abundance effectively. Accordingly, owing to the significance of MPs' high abundance in urban ditches, they are considered valuable indicators of those ditches pollution into the nearby water bodies (Chaukura et al., 2021).

The city of Bahir Dar is at the mouth where one of Africa's biggest lakes (Lake Tana) flows out into rivers (Abay River/The Blue Nile) and is a leading tourism destination in Ethiopia, located $578 \mathrm{~km}$ north-northwest of Addis Ababa. The city area is surrounded by a variety of natural attractions, with both lakes and rivers providing a favorable habitat for people in the country, being a highly-populated area with a proliferation of congested slums leading to plastic pollution. However, there is a lack of reports on plastic waste generation, distribution, and the occurrence of MPs in the city. Of note is that the pollution level is to date unknown for the majority of metropolitan cities in the country, Bahir Dar being one of them. Thus, acknowledging the problems of contamination by MPs, effective monitoring of these contaminants is necessary, especially in respect of the big metropolitan cities within which high consumption of single-use plastics is known to be taking place. Accordingly, this study aimed at the four large ditches of Bahir Dar City to investigate the occurrence, abundance, and identification of MPs, also to predict its impact on nearby water bodies (Lake Tana and the Abay River).

\section{METHODS}

\section{Description of the Study Area and Site Selection \\ Study Area Description}

Bahir Dar is the capital city of the Amhara National Regional State (ANRS) in Northern Ethiopia. It is situated close to Lake 


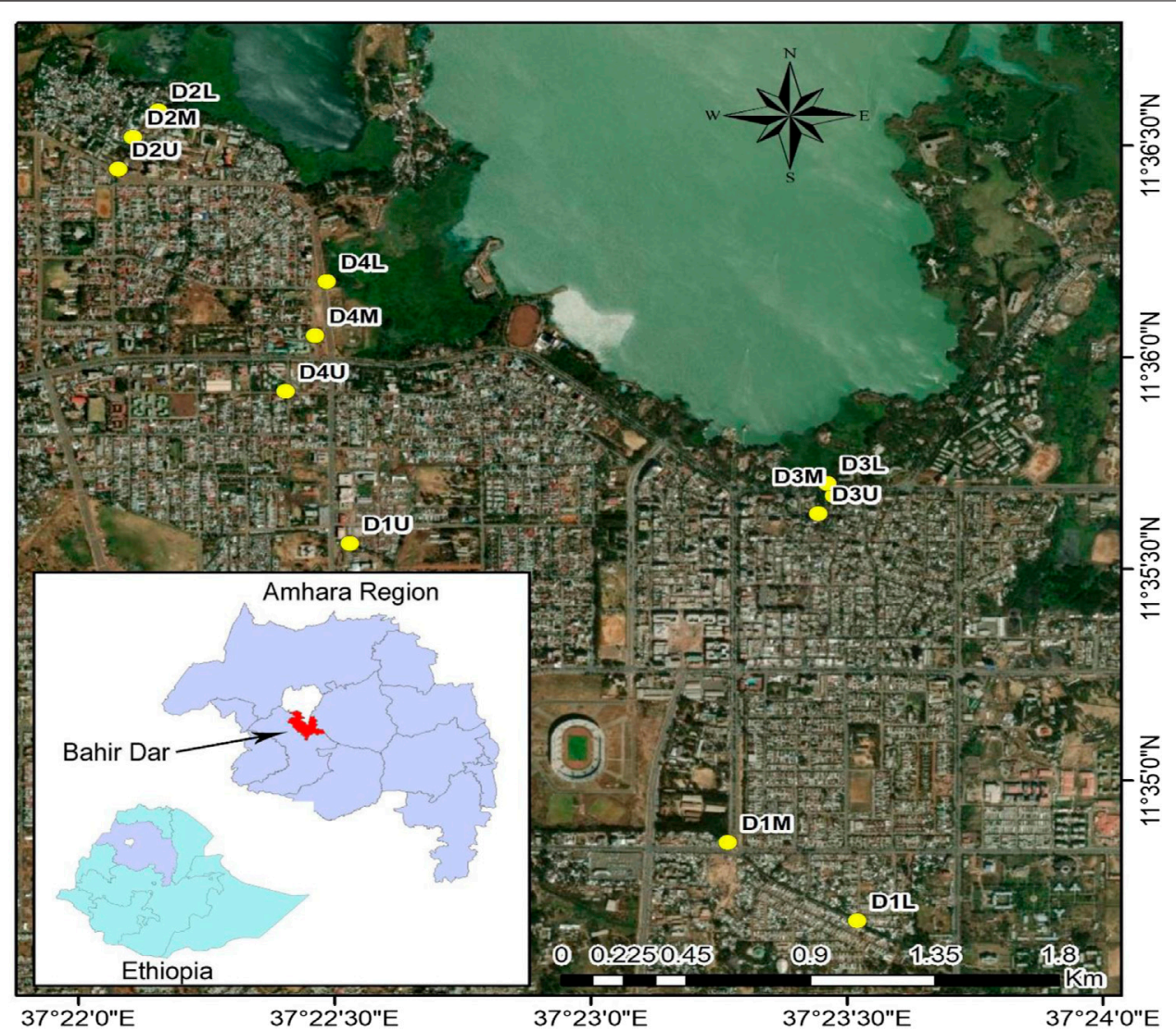

FIGURE 1 | Map of the study area with the three locations at each of the four major ditches in the city. Yellow dots indicate sampling locations.

Tana, the headwaters of the Blue Nile, and is a significant vacationer city in Ethiopia (Fenta, 2017). It has a level earth structure which is located at $11.5742^{\circ} \mathrm{N}, 37.3614^{\circ} \mathrm{E}$, and expanded quickly throughout the 20th century; today, sewage release into Lake Tana and the Blue Nile has turned into a genuine and profoundly noticeable problem (Tassie and Endalew, 2020). The name Bahir Dar is associated with its nearness to the two water assemblages of Lake Tana and River Abay (Blue Nile). Mainly, the following criterion described Bahir Dar city to be the study area for this research: 1) It is one of the fast-growing cities in the country that resulted in the presence of widespread plastic waste regarding slum houses in the city. 2) There is no reported research so far on the occurrence, abundance, composition, and quantification of plastic waste and MPs in the city, generally or at a country level. 3) Because the city has several historical places, active tourism results in the improper disposal of huge amounts of plastic waste. 4) The city also has different topographical urban catchments that each convey the urban storm runoff to separate outfalls. 5) Currently, the urban runoff and municipal agglomerated sewage water are discharged to the nearby natural water bodies.

\section{Selection and Description of the Site}

The main four representative ditches in the city were selected based on their long areas of coverage, terminating near to and/or in natural water bodies, which can be a main contributor of MPs to Lake Tana and the Blue Nile River.

$\checkmark$ Ditch1 (D1): The main effluents canal that starts from wetlands (the Gudo Bahir), located on the north side of the city. It discharges its effluents which contain municipal wastewater and stormwater directly in to head of the Blue Nile River. It is the biggest canal, into which many residents discharge their waste.

$\checkmark$ Ditch2 (D2): It an institutional area around a referral hospital (the Felege HIWOT Regional Referral Hospital) in the city to which most plastic waste occurs and rainwater run-off is transported to the ditch, to which rectangular masonry storm drains were connected. In addition, the concrete pipe found in this sub-catchment is the one that is, laid along the street area where head offices, commercial activities, and hotels are found. Furthermore, the main road to the airport joins the ditches that guide floods to this ditch.

$\checkmark$ Ditch3 (D3): This ditch is found in the central area of the city between "Dib Anbessa" and the "Naky" international Hotels and crosses several restaurants, small hotels, and other commercialpremises. In this ditch, on one side there is monitoring of major flows in the main street that stretches from the Saint George Church to the regional council bureau. On the other side, it is found near the "Summerland International Hotel" and carries the waste plastics discharged by hotel users and 
pedestrians. This sampling site enabled an assessment of the quantity and quality of MPs discharged from around hotels. It also represents the total surface runoff exiting in this sub-basin.

$\checkmark$ Ditch4 (D4): Located at the North-western end of the city, it collects most of the urban runoff from the new residential area and small farm areas. The stormwater and runoff at this sampling site are supplied by mixed types of various small drainage ditches. The drainage ditches running through the main street to this outfall point are earthen open ditches whereas the other feeder ditches are rectangular masonry open ditches. The maps were plotted and described using ArcGIS (version 10.7) as shown in Figure 1.

\section{Sample Collection}

Sediment and agglomerated sewage water samples were collected from 12 sampling locations (upper, middle, and downstream) of four ditches (three locations on each ditch). In total $12 \mathrm{Kg}(1 \mathrm{Kg}$ on each location) of sediment samples at the top $2.5 \mathrm{~cm}$ of the layer were collected using a pre-cleaned stainless-steel shovel (Zobkov and Esiukova, 2018). Also, $12 \mathrm{~L}$ (1 L on each location) of agglomerated sewage water was collected using stainless-steel buckets (Zobkov and Esiukova, 2018). Most studies focus on the MPs present in the top $(0-5 \mathrm{~cm})$ surface depth, as the surface layer of the compartments (Sediment and Agglomerated sewage water) are regarded as the most polluted layer (Willis et al., 2017). Quadrats of $1 \mathrm{~m} \times 1 \mathrm{~m}$ were used to delineate the scope of the sediment collection (Jiang et al., 2018). According to the report by Xu et al. (2019), samples collected at different positions in the same location were pooled together and sealed correctly (Xu et al., 2019). To minimize the external MP contamination, gloves and cotton clothes were used during the sampling process. According to Jian et al. (2018) report, all samples were collected in the dry season (April 2021 for this study). This is because rainfall and runoff in the rainy season have a potential impact on the quantification and identification of MPs (Jian et al., 2018). Collected samples were immediately transferred to the laboratory and stored at $4^{\circ} \mathrm{C}$ by sealing in a perfect tin-foil sack to prevent physicochemical characteristic changes of the MPs in sediment and water matrices (Leslie et al., 2017). The MPs extraction was carried out as per the National Oceanic and Atmospheric Administration protocols with some modifications (Masura et al., 2015).

\section{Extraction and Separation Processes}

In this study, aqueous zinc chloride $\left(\mathrm{ZnCl}_{2}\right)$ solution having a density value of $1.6 \mathrm{~g} \mathrm{~cm}^{-3}$ for sediment samples and saturated sodium chloride $(\mathrm{NaCl})$ having a density of $1.2 \mathrm{~g} \mathrm{~cm}^{-3}$ for agglomerated sewage water sample was prepared. From the total collected $1 \mathrm{Kg}$ of sediment and $1 \mathrm{~L}$ of agglomerated sewage water sample at each location, $50 \mathrm{~g}$ sediment, and $50 \mathrm{ml}$ of agglomerated sewage water were measured and mixed using $250 \mathrm{ml}$ of aqueous solution $\mathrm{ZnCl}_{2}$ and $50 \mathrm{ml}$ saturated $\mathrm{NaCl}$ solution in $500 \mathrm{ml}$ glass beakers respectively. The extraction procedure was conducted according to the method reported by Zheng et al. (2019) and a triplicate replica was carried out using $50 \mathrm{~g}$ sediment and $50 \mathrm{ml}$ agglomerated sewage water (Zheng et al., 2019).

A $50 \mathrm{ml}$ saturated $\mathrm{NaCl}$ solution was mixed with $50 \mathrm{ml}$ agglomerated sewage water and shaken thoroughly to separate the MPs. Low-density MPs such as PE $\left(0.91-0.98 \mathrm{~g} / \mathrm{cm}^{3}\right)$ and PP $\left(0.89-0.92 \mathrm{~g} / \mathrm{cm}^{3}\right)$ were successfully separated from the sediment and agglomerated sewage water sample with saturated $\mathrm{NaCl}$ solution. But it was only suited to separate MPs with a density of below $1.20 \mathrm{~g} / \mathrm{cm}^{3}$. High-density MPs, such as PVC $\left(1.16-1.58 \mathrm{~g} / \mathrm{cm}^{3}\right)$ and PET $\left(1.37-1.45 \mathrm{~g} / \mathrm{cm}^{3}\right)$ were not completely separated. Therefore, MPs with high density were separated using $\mathrm{ZnCl}_{2}$ solution $(1.6 \mathrm{~g} / \mathrm{cm} 3)$ for sediment samples. Then after the mixture was poured gradually into the sample beaker while mixing the sample with a stainless-steel spatula for about $10 \mathrm{~min}$ and leaving them overnight to sedimentation. Visible floating plastic particles with a particle size greater than $5 \mathrm{~mm}$ were picked using metal forceps and stored in an appropriate place.

In the density separation process, two steps were included to separate MPs from the mixture. 1) The first step was the separation of $>0.5 \mathrm{~mm}$ particles from the mixture using a metal sieve having a mesh size of $0.5 \mathrm{~mm}$. The separated particles on the metal sieve were left to dry for sufficient hours, collected, and stored for polymeric identification of the MPs. Only particles large enough to manipulate by hand, approximately $>0.5 \mathrm{~mm}$, were subjected for identification with Fourier transform infrared (FTIR) spectroscopy. Particles smaller than $0.5 \mathrm{~mm}$ were not used for identification due to the lack of accurate analytical techniques (such as $\mu$ - FTIR spectroscopy) (Werbowski et al., 2021). 2) The second step was the separation of MPs within the particle size of $<0.5 \mathrm{~mm}$ from the subsequent supernatant using vacuum filtration through Mixed-Cellulose Ester filters after the oxidation process.

\section{Digestion and Filtration Processes}

The biological tissues and organic matter were removed from the supernatant by oxidizing them with $30 \% \mathrm{H}_{2} \mathrm{O}_{2}(50 \mathrm{ml})$ and $0.05 \mathrm{M} \mathrm{Fe}$ (II) $(50 \mathrm{ml})$ mixtures. The digestion process was continued until the digestion liquid became clear (Masura et al., 2015). The mixture was left for $5 \mathrm{~min}$ at room temperature before the heating process was started, wherein the mixture was put on the hotplate for hot digestion. The temperature was kept under $70^{\circ} \mathrm{C}$. After thorough digestion, the mixtures were removed from the hotplate and allowed to cool down and kept for filtration.

After digestion of the supernatant, vacuum filtration was conducted to separate the $<0.5 \mathrm{~mm}$ MPs using a cellulose nitrate (Mixed-Cellulose Ester) membrane filter. The filtration process was conducted by pouring the supernatant on a membrane filter placed on a Buchner funnel while the vacuum pump was on. The cellulose nitrate filter paper used has $47 \mathrm{~mm}$ diameter, and $0.45 \mu \mathrm{m}$ pore size with a slow filtration rate, and particle retention was from 0.004172 to $0.5 \mathrm{~mm}$ (Desforges et al., 2014). The particles retained from the filter were placed in a precleaned glass petri dish for subsequent analyses.

\section{Identification}

\section{Visual and Microscopic Examination}

Identification includes direct observation of MPs by the naked eye (from 0.5 to $5 \mathrm{~mm}$ particle size) and microscopic Examination (< $0.5 \mathrm{~mm}$ particle size $)$. The MPs $(>0.5 \mathrm{~mm})$ that were retained on 

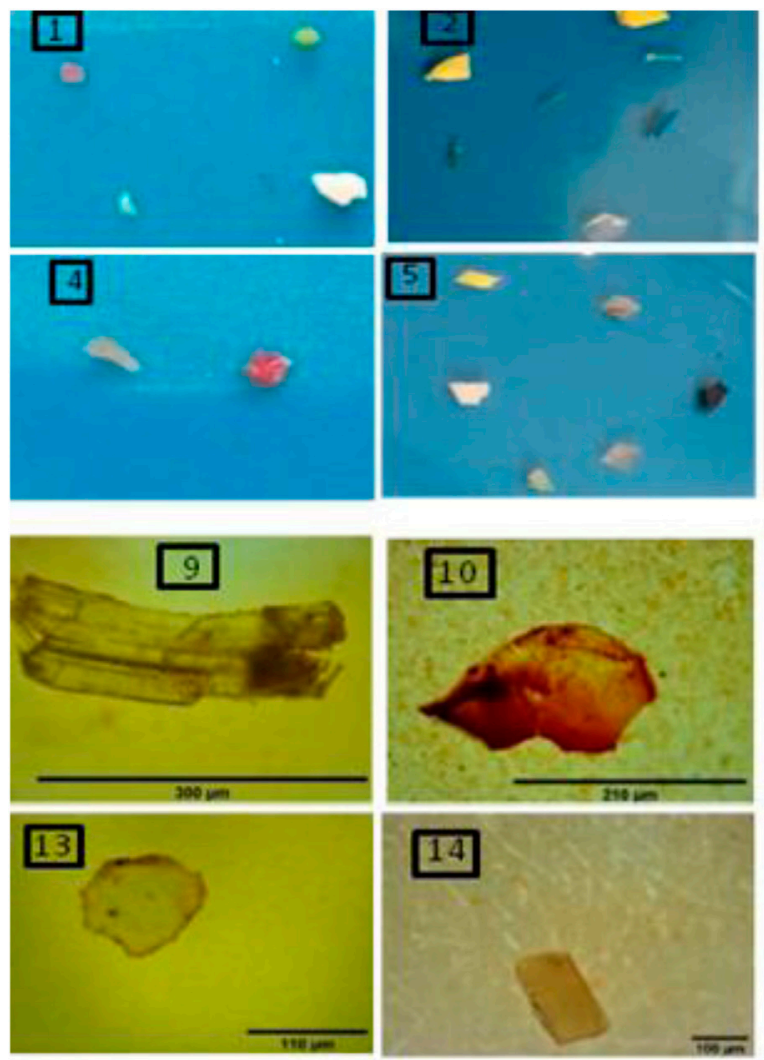
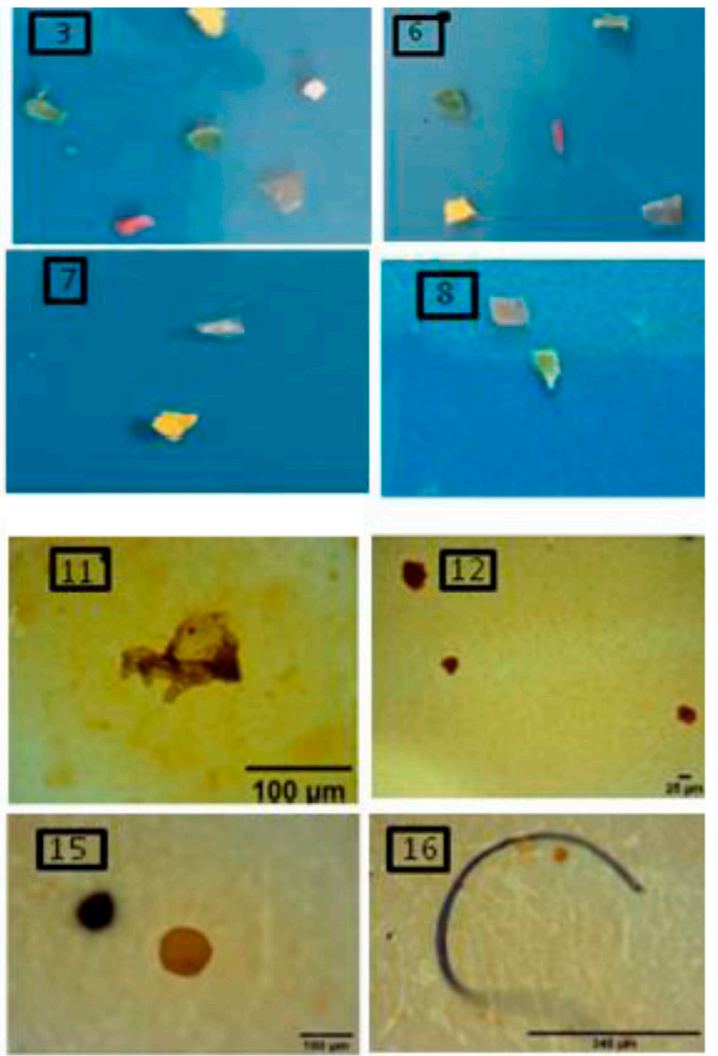

FIGURE 2 | Pictorial representation of some of the identified MPs in different sizes, shapes, and colors in sediment and agglomerated sewage water samples with greater than $0.5 \mathrm{~mm}(1-8)$ and less than $0.5 \mathrm{~mm}(9-16)$.

TABLE 1 | Occurrence (Mean \pm SD) comparison of MPs in the ditch sediments and agglomerated sewage water samples at three sampling locations of each ditch (a) $0.00417-0.5 \mathrm{~mm}$ particle size and (b) $0.5-5 \mathrm{~mm}$ particle size.

\begin{tabular}{|c|c|c|c|c|c|}
\hline \multicolumn{2}{|c|}{ Ditches and locations } & \multicolumn{2}{|c|}{$0.00417-0.5 \mathrm{~mm}$} & \multicolumn{2}{|c|}{$0.5-5 \mathrm{~mm}$} \\
\hline & & Sediment & Water & Sediment & Water \\
\hline Ditch & Locations & Items $/ 50 \mathrm{~g}$ & Items/50 ml & Items $/ 50 \mathrm{~g}$ & Items $/ 50 \mathrm{ml}$ \\
\hline \multirow[t]{3}{*}{1} & Upper stream (D1U) & $2 \pm 1.00$ & $1.33 \pm 0.58$ & $2.00 \pm 1.00$ & $1.33 \pm 0.58$ \\
\hline & Middle stream (D1M) & $2.33 \pm 0.58$ & $1.67 \pm 0.58$ & $2.00 \pm 1.00$ & $1.33 \pm 0.58$ \\
\hline & Lower stream (D1L) & $5 \pm 1.00$ & $3.00 \pm 1.00$ & $2.33 \pm 0.58$ & $1.00 \pm 0.00$ \\
\hline \multirow[t]{3}{*}{2} & Upper stream (D2U) & $1.33 \pm 0.58$ & $1.67 \pm 1.23$ & $1.67 \pm 0.58$ & $1.33 \pm 0.58$ \\
\hline & Middle stream (D2M) & $2.33 \pm 0.58$ & $2.00 \pm 1.00$ & $1.67 \pm 1.15$ & $1.33 \pm 0.58$ \\
\hline & Lower stream (D2L) & $3.33 \pm 0.58$ & $2.67 \pm 0.58$ & $1.33 \pm 0.58$ & $0.67 \pm 0.58$ \\
\hline \multirow[t]{3}{*}{3} & Upper stream (D3U) & $1.67 \pm 0.58$ & $1.67 \pm 0.58$ & $1.00 \pm 0.00$ & $1.00 \pm 0.00$ \\
\hline & Middle stream (D3M) & $1.67 \pm 0.58$ & $1.33 \pm 0.58$ & $1.33 \pm 0.58$ & $1.00 \pm 0.00$ \\
\hline & Lower stream (D3L) & $3 \pm 1.00$ & $2.67 \pm 0.58$ & $1.33 \pm 0.58$ & $1.33 \pm 0.58$ \\
\hline \multirow[t]{3}{*}{4} & Upper stream (D4U) & $1.33 \pm 0.58$ & $1.00 \pm 0.00$ & $1.33 \pm 0.58$ & $1.00 \pm 0.58$ \\
\hline & Middle stream (D4M) & $1.33 \pm 0.58$ & $1.33 \pm 0.58$ & $1.33 \pm 0.58$ & $0.67 \pm 0.58$ \\
\hline & Lower stream (D4L) & $1.33 \pm 0.58$ & $1.67 \pm 0.58$ & $0.67 \pm 0.58$ & $0.67 \pm 0.58$ \\
\hline
\end{tabular}

the sieve were simply observed by the naked eye and sorted by their physicochemical characteristics. On the other hand, MPs (< $0.5 \mathrm{~mm}$ particle size) that were placed in a pre-cleaned petri dish were analyzed using ImageJ software (ij152-win-java8) to determine their particle size according to (Qi et al., 2020). Moreover, a compound microscope with an attached digital camera (NLCD-120E) was used to determine the quantity, shape, and color of MPs (Hazimah et al., 2014). A covered plate sample was subjected for examination and observed with $\times 10$ magnifications. Then after MPs particles were identified and measured according to their physical characteristics, following the method described by Hazimah et al. (2014) report (Hazimah 
et al., 2014). The number, shape, color, and size of the particles were recorded. The size of the plastic particles was recorded from 0.004172 to $0.5 \mathrm{~mm}$. Particles that were smaller than $0.004172 \mathrm{~mm}$ were not included in this study.

\section{Polymer Type Identification}

Sieve-based separated MPs (> $0.5 \mathrm{~mm}$ ) were analyzed for polymeric identification using FTIR Spectrometer (JASCO6600 spectrometer) with a scanning range from 400 to $4,000 \mathrm{~cm}^{-1}$. Particles were manually pressed into pellets, and the analysis mode was set to percentage transmittance $(\% \mathrm{~T})$. The instrumental parameters were set as per the manufacturer's protocol. As a comparison, the plastic polymers collected from Amhara Pipe Factory were analyzed as standard. Large-sized MPs particles $(0.5-5 \mathrm{~mm})$ were picked from the sieve using cleaned forceps and placed in a plastic pellet holder, and subjected for spectral analysis according to the report by Veerasingam et al. (2020). The infrared spectra having a similar peak with the standard reference polymeric plastic were assigned as PP, PE, PVC, etc. The spectral peaks obtained were analyzed and interpreted with the literature survey to analyze the nature of the plastic polymer composition identified from sediment and agglomerated sewage water samples.

\section{Quality Assurance and Quality Control}

In the laboratory, a series of measurements were taken to avoid potential background contamination. Gloves and cotton lab coats were worn during the experimentation time. All of the solutions used in the study were filtered through a $0.45-\mu \mathrm{m}$ filter before using for the experiments. Tools, glassware, and containers were thoroughly rinsed with deionized water and covered with aluminum foil after each step. All synthetic clothes were refused while doing microscopic analysis to reduce the other contamination.

\section{RESULT AND DISCUSSION}

Some of the pictorial and microscopic image representation of identified MPs in different sizes, shapes, and colors in sediment and agglomerated sewage water is shown in Figure 2. Particles were recorded through their plastic characteristics, such as the absence of cellular structures, the constant thickness of fragments and fibers, homogeneous color and brightness, and equal roundness throughout the entire length and not segmented into fibers. Such particles were identified as MPs and observed (Hazimah et al., 2014). This suggests that all identified particles irrespective of their color and shape were MPs.

\section{Occurrence and Abundance of MPs}

In the present study, a total of $239 \mathrm{MP}$ particles were obtained. In sediment samples, a total of 135 MPs (55 items for particle size $0.5-5 \mathrm{~mm}$ and 80 items for particle size $0.00417-0.5 \mathrm{~mm}$ ) were found, and $104 \mathrm{MP}$ particles (38 items for particle size $>0.5 \mathrm{~mm}$ and 66 items for particle size $<0.5 \mathrm{~mm}$ ) were identified in agglomerated sewage water samples. As shown in Table 1, for all particle sizes classifications, the mean value range was recorded as from $1.33 \pm 0.58$ to $5 \pm 1.00$ Items $/ 50 \mathrm{~g}$ and $1.00 \pm 0.00$ to $3.00 \pm 1.00 \mathrm{Items} / \mathrm{ml}$ for $0.00417-0.5 \mathrm{~mm}$ in sediment and agglomerated sewage water samples, respectively. Also, the mean value range for the particle size of $0.5-5 \mathrm{~mm}$ was recorded (Table 1) as from $0.67 \pm 0.58$ to $20.33 \pm 0.58$ items $/ 50 \mathrm{~g}$ and $0.67 \pm 0.58$ to $1.33 \pm 0.58$ items $/ \mathrm{ml}$ in sediment and agglomerated sewage water samples, respectively. The highest occurrence of MPs was observed in the downstream sampling locations of the ditches in both the sediment and water agglomeration. However, the lowest occurrence of MPs, onethird of that of the lower stream, was recorded in the upper stream sampling location of the ditches for particles size having $<0.5 \mathrm{~mm}$. This suggests that the side-feed of the urban municipal wastewater, flashes, and other sources of MPs may accumulate at the downstream area in that the upper stream can be considered as the point source of pollutants to the lower streams (Espiritu et al., 2019).

For both sediment and agglomerated sewage water samples, the highest abundance of MPs was observed at the lower stream sampling location at D1, except for $0.5-5 \mathrm{~mm}$ in the water sample only. This indicates that the ditch is seriously polluted with municipal agglomerated sewage MPs from the encompassing residential area, government offices, restaurants, and tourism which is identified with excessive disposal of plastic wastes. Also, floods, mixed with sewage, in the rainy season may discharge to the ditch and wash them to the downstream area. Thus, the discharged municipal wastewater and surface runoff may be the major MPs pollution contributors, being highly abundant in this location as compared with other sampling sites (Li et al., 2018). Moreover, a similar phenomenon was recorded in another big ditch (D2) which is the secondhighest important source of MPs. The abundance of MPs tends to increase gradually from upper to lower stream for particle size of $0.00417-0.5 \mathrm{~mm}$ in sediment and agglomerated sewage water samples. However, the reciprocal occurs for particle size of $0.5-5 \mathrm{~mm}$ except for the middle stream of the ditch. This contradiction event may be due to the limited path length of the plastic wastes flowing through the ditch resulted in a low breakdown into MPs (Shahul Hamid et al., 2018). Therefore, the abundance of MPs is highly dependent on the source of the main activities, the pathway, and the path length that the plastic wastes can be subjected to the weathering condition. For example, huge amounts of agglomerated sewage effluents from domestic wastewater and surface runoff from populated areas may transport plastics into the urban ditch, resulting in a high abundance of MPs (Gies et al., 2018).

The third highest MPs abundance was recorded from ditch 3 (D3) at the lower stream sampling locations for both $0.00417-0.5 \mathrm{~mm}$ and $0.5-5 \mathrm{~mm}$ particles sizes in sediment and water samples. This is because the sampling locations exhibit high population densities and are open to the public for recreational activities, resulting in high single-use plastic consumption and incorrect disposal, possibly serving as an important MP contributor (Schnurr et al., 2018). Also, several hotels and guest houses exist in this area.

At ditch 4 (D4), around the "National Fuel Depot" sampling location, on average there was the lowest abundance of MPs (for 

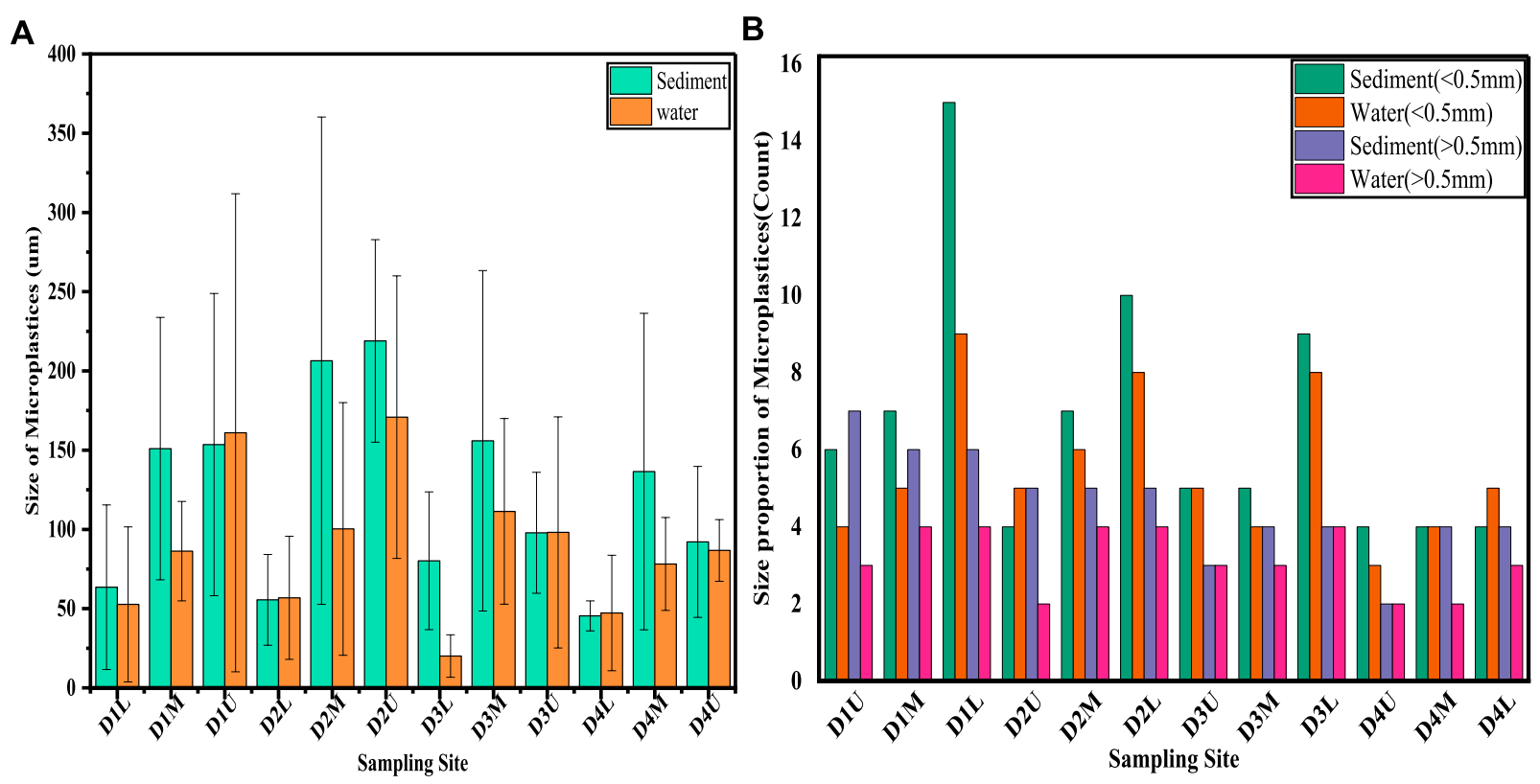

FIGURE 3|Mean size ( \pm SD) of MPs in sediment and agglomerated sewage water samples at each sampling location for four ditches (A) $0.00417-0.5$ mm and (B) proportion of MPs for large and small size particles.

the three streams) recorded as compared with the other ditches. The least number of MPs abundance was found at the upper stream of this ditch in water samples for $0.00417-0.5 \mathrm{~mm}$ and in both sediment and agglomerated sewage water samples for $0.5-5 \mathrm{~mm}$ particles size as compared with the lower and middle streams. This indicates that the area is less affected by plastic waste due to less population density and fewer commercial activities as compared to the other three ditches. Also, the surface runoff and sewage wastewater are the least source of pollution for D4, rather than direct flooding to the nearby natural body of water, Lake Tana. Generally, the distribution patterns, abundance, contamination level, and pathway of MPs in urban ditch sediments and agglomerated sewage water are highly influenced by anthropogenic activities, prior significant contributors to plastic pollution, topography, geography, and weathering conditions (Tibbetts et al., 2018).

Moreover, the distribution pattern of MPs in ditches also agrees with the hypothesis that the high-water discharge would shift plastic particles to the lower part of the watershed (Birch et al., 2020). In the present study, the average MP concentration in sediment at the D1 was recorded approximately twice as that of the D3 and three times higher than that of the D4 areas. This indicates that the plastic particles shift may occur by water discharges and with other anthropogenic and natural influential factors in such a way that MPs can easily enter the surface water and/or accumulate in the sediment sample. In addition, no significant correlation was observed between MPs abundance in agglomerated sewage water and sediment samples may be due above-mentioned reasons, and other complicated factors (e.g., water quality, water flow, and the characteristics of MPs). In conclusion, it is essential to control the discharge of municipal wastewater into the natural environment including natural bodies of water and urban ditches.

\section{Physicochemical Characteristics of MPs Size of MPs}

We compared the size proportioned abundance of MPs for both the large and small-sized classification in agglomerated sewage water and sediment samples for each sampling location. The proportion of MPs size, as shown in Figure $\mathbf{3 B}$, of $0.00417-0.5 \mathrm{~mm}$ was recorded as the most abundant particle size range in both water and sediment samples, particularly at the lower stream sampling locations compared to the $>0.5 \mathrm{~mm}$ particle size of MPs. MPs with a size $<0.5 \mathrm{~mm}$ comprised $61.09 \%$ of the identified plastic particles, whereas the MPs with a size $>0.5 \mathrm{~mm}$ were only $38.91 \%$. As shown in Figure $3 \mathbf{A}$, the lower stream of the ditches is polluted with very small MPs particles from both sediment and agglomerated sewage water. The smallest mean size of MP particles was found from D3 at the lower stream sampling location in the agglomerated sewage water samples. Therefore, the high percentage of small-sized MPs indicates a higher probability of ingestion events for aquatic organisms, since their fine size is similar to zooplankton to suspend in waters (Cole et al., 2011; Botterell et al., 2019).

Small-sized MPs are mainly fragmented from larger plastic debris by various weather condition impacts such as mechanical forces, photo-degradation, and biodegradation processes (Zbyszewski et al., 2014). They are considered to pose a more serious potential threat to aquatic organisms than large-sized MPs due to their greater surface area for possible adsorption of associated contaminants (Devriese et al., 2017). The ingestion of 

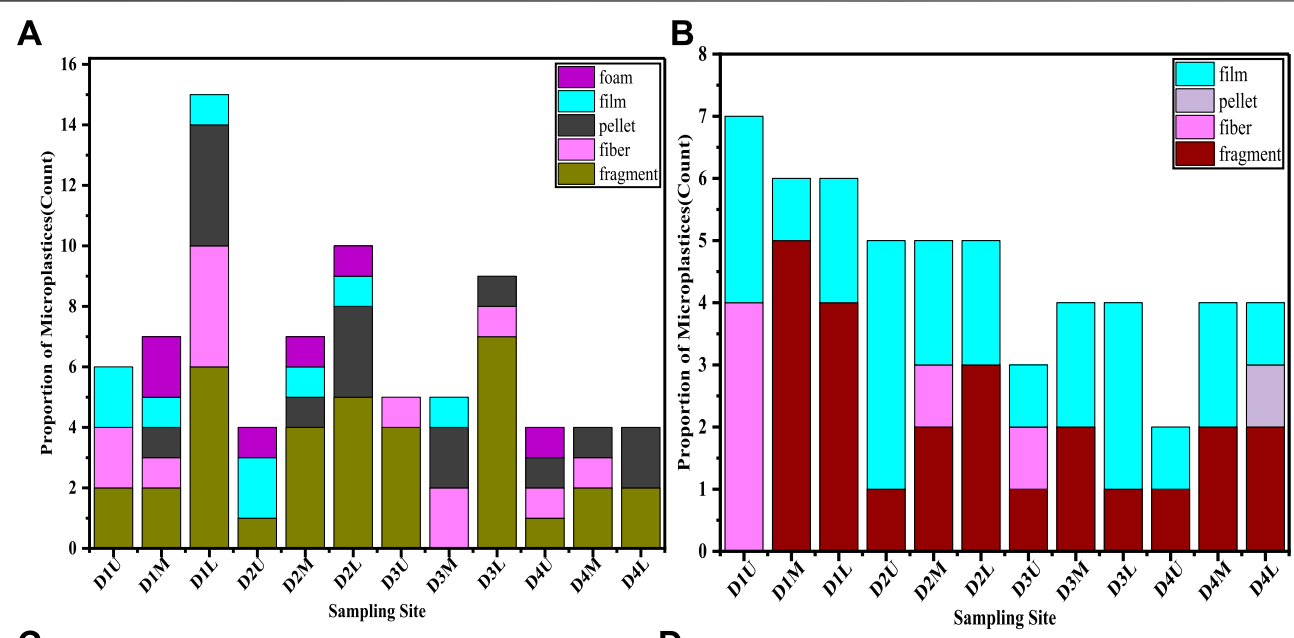

D
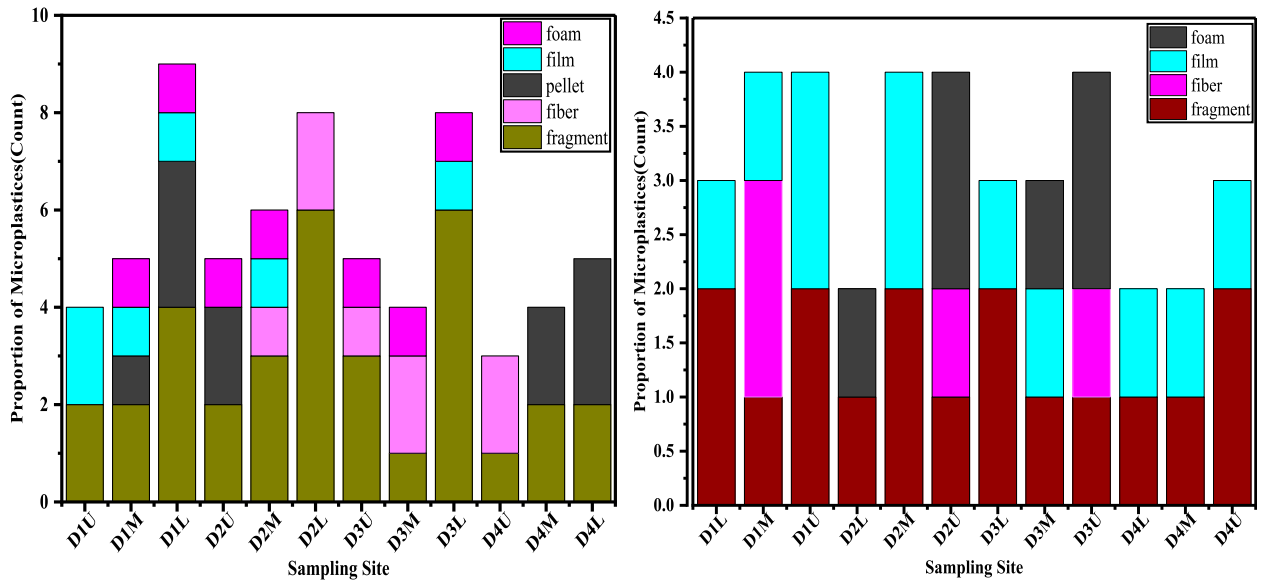

FIGURE 4 | MPs shape proportion from sediment (A,B) and agglomerated sewage water samples (C,D) across all sampling locations of each ditch for particle size $<0.5 \mathrm{~mm}(\mathbf{A}, \mathbf{C})$ and $>0.5 \mathrm{~mm}$ (B,D)

MPs by both low trophic and high trophic organisms, and both vertebrates and invertebrates, has caused adverse health effects (Ivar and Costa, 2014). As with the results of many published studies, the size of MPs in this study was inversely proportional to their quantity (Triebskorn et al., 2019). This may be due to that large-sized MP could be fragmented into several smaller particle sizes by the matrices effect from the municipality (Song et al., 2017). Moreover, small size MPs have high specific surface areas resulting in easy to form biofilms by adsorbing different chemical substances (Selvam et al., 2021a). This results from the increased density and eases entry into the sediment matrix (Triebskorn et al., 2019). Also, MPs with relatively lower density and smaller size can increase travel further on the wind and waves.

\section{Shape of MPs}

Different shapes of MP particles (fragment, fiber, film, pellet, and foam) of various quantities across sampling locations, were recorded as shown in Figure 4. As can be seen in Figure 4, fragment MPs were recorded as the dominant shape for both of the two size classifications in both sediment and agglomerated sewage water samples. Per the particle size ranges from 0.00417 to $0.5 \mathrm{~mm}$
(Figures 4A,C) and from 0.5 to $5 \mathrm{~mm}$ (Figures 4B,D), they were recorded in all sampling locations except a middle stream from D3 (for $0.00417-0.5 \mathrm{~mm}$ particle size) and the upper stream from D1 (for $0.5-5 \mathrm{~mm}$ particle size) in sediment samples. The proportion of fragment MPs was $45 \%$ and $51 \%$ for particle size $<0.5 \mathrm{~mm}$ in sediment and agglomerated sewage water samples, respectively. In addition, $43 \%$ in sediment and 58\% in the Agglomerated sewage water samples were found for particle sizes $>0.5 \mathrm{~mm}$. A possible reason for the wide distribution of fragment MPs is that they come from the widest range of plastic waste in the urban area that can be degraded and fragmented from plastic bags, plastic bottles, packaging materials, containers, and toys used in a daily manner (Zhao et al., 2015; Peng et al., 2018). In the present study, it can be suggested that the fragment particles abundance rate in agglomerated sewage water was high as compared with sediment samples. Perhaps, fragment MP particles surface area to volume ratio is high as compared with fibers and film resulted in the particles being able to float out on the top of the agglomerated sewage water.

The second most abundant type of MPs is in the sediment and agglomerated sewage water. Samples were recorded as films with the proportion of $11 \%$ and $9 \%$ (for particle size $<0.5 \mathrm{~mm}$ ) and 
A

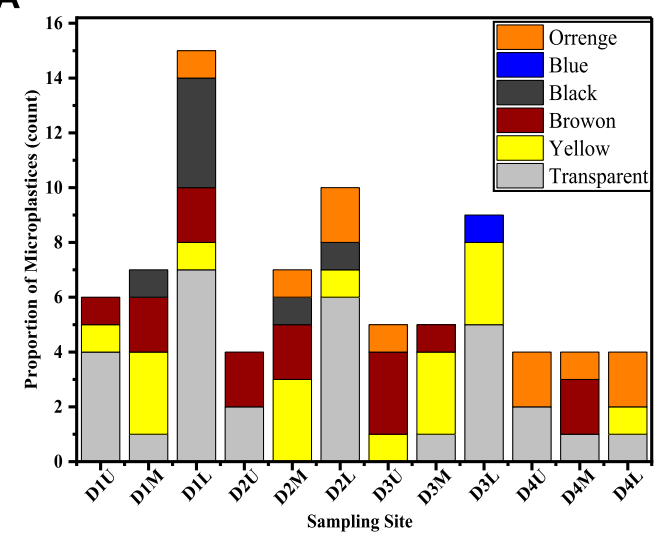

C

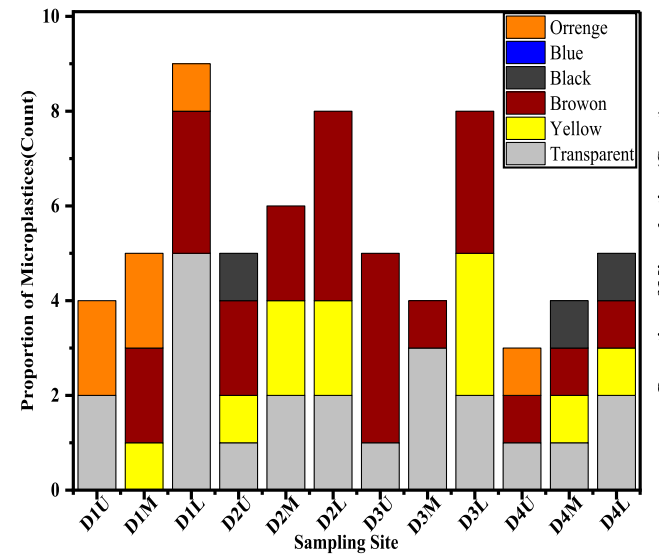

B

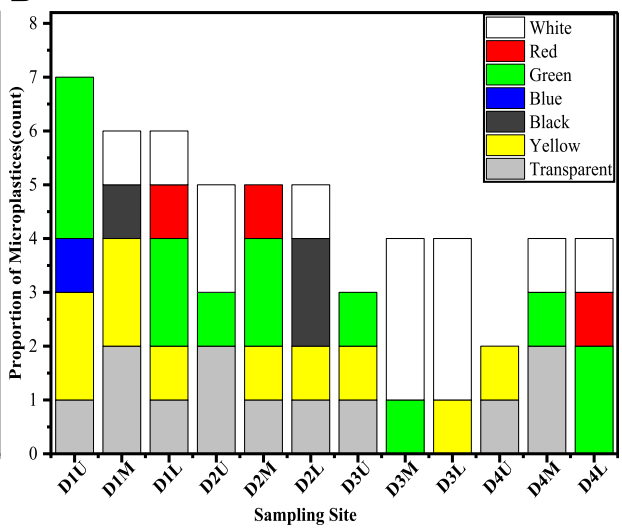

D

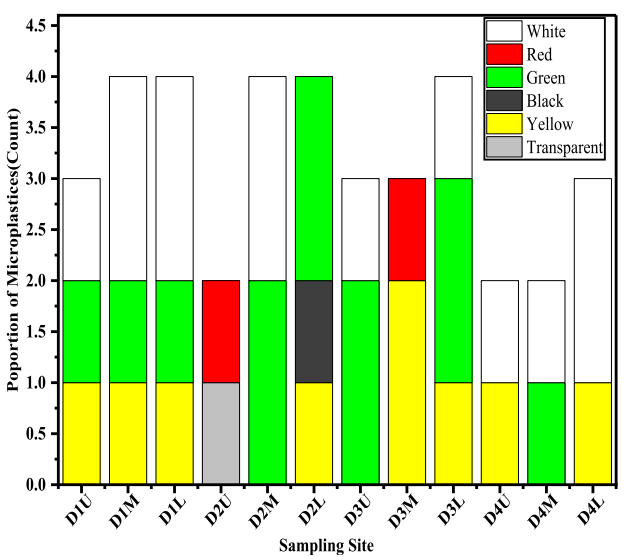

FIGURE 5 | The color proportion of MPs from sediment sample (A,B) and agglomerated sewage water sample (C,D) across all sampling locations at each ditch for particle size $<0.5 \mathrm{~mm}(\mathbf{A}, \mathbf{C})$ and for $>0.5 \mathrm{~mm}$ (B,D).

$43 \%$ and $26 \%$ (for particle size $>0.5 \mathrm{~mm}$ ) in sediment and agglomerated sewage water samples, respectively. Films are mainly generated by the fragmentation of plastic carrier bags (Hazimah et al., 2014). Film types of MP shapes are also can be formed from the degradation of daily used plastic that comes from agricultural films, an impermeable plastic film (Ding et al., 2019). Mainly, the film particles sources are from thinner, and softer plastic debris (Teuten et al., 2007). This suggests that this kind of plastic material has been disposed to urban ditches where the samples were collected.

The third abundant MPs particle were recorded as fiber type found in both sediment and agglomerated sewage water samples. The fiber type of MPs often exists in water from laundry and daily cleaning microfiber-like products from cosmetics and disposable facial towels are major sources. The washing machines of fabrics releases thousands of fiber type of MPs into domestic wastewater through the urban ditches (Hernandez et al., 2017). The proportion of fiber was recorded at $16 \%$ and $12 \%$ (for particle size $<0.5 \mathrm{~mm}$ ), and $6 \%$ and $11 \%$ (for particle size $>0.5 \mathrm{~mm}$ ) in sediment and agglomerated sewage water, respectively. As compared with fragment and film shape MPs, fiber is the least proportion at most of the sampling locations suggests that may the relatively fewer sources in the studied area. The fact that fiber particles are generated from wastewaters of laundering (De Falco et al., 2019) suggests that the fiber sources in the city exist in small proportions. The pellet MP particles were recorded in small proportion as compared with the other shapes (fragment, film, and fiber), even so there was a record at most of the sampling locations. This is due to the source of the pellet shape usually being primary MP such as microbeads and plastic pellets (Turner, 2018), and they are mainly originated from daily personal care products, such as cosmetics and cleaning media (Napper et al., 2015). This indicates that pellets from personal daily care products such as toothpaste and shampoo usage and disposal in the city are minimal. Pellets were observed in a low proportion in agglomerated sewage water compared to in sediment. The other Proportionally small shape of MPs in the present study were recorded as foam. The density of foams is low and thus they easily float on the surface water and are assumed to be minimal or leave no record in the sediment samples. However, the foam had large numbers of gas micropores and thus can easily adsorb different substances (Selvam et al., 2021a) resulting in enlargement and making foams denser and able to sink into the sediment (Hazimah et al., 2014). Thus, in the present study, the foam was recorded in some sampling locations for both sediment and agglomerated sewage water samples, showing no particular trend. 


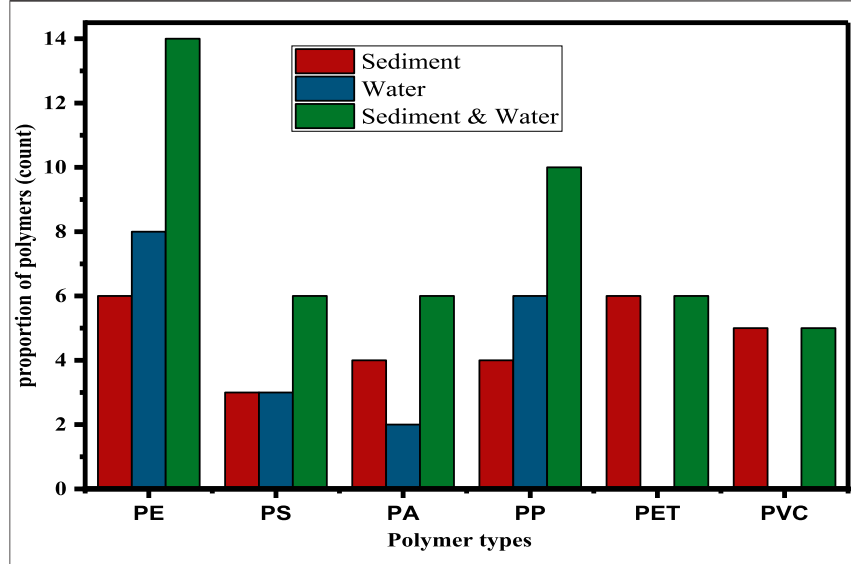

FIGURE 6 | Identified MPs polymeric proportion in sediment and water sample, and total contributions.

\section{Color of MPs}

The color of the MPs particles is an important factor enhancing the likelihood of ingestion by the marine organisms for resembling their target prey. Some commercial fish species (Selvam et al., 2021b) and their larvae may target tiny zooplankton and they have a higher chance of ingesting transparent/white and yellow MPs as they are visual predators (Zhao et al., 2015). In the present study, various colors were recorded across all sampling locations as shown in Figures 5A-D. Transparent MPs were recorded as the most frequently abundant type of particles along the four ditches for both sediment and agglomerated sewage water samples for particles $<0.5 \mathrm{~mm}$, which is similar to (Zhang et al., 2018; Zhao et al., 2020). This suggests that colored plastic polymers are not frequently used in commercial goods in contrast with colorless (white/ transparent) plastic materials (Klein et al., 2015). Disposable plastics such as plastic bags, plastic cups, and bottles have short lifetimes and might be the potential source of transparent MPs in urban municipalities (Xiong et al., 2018; Prata et al., 2019). In addition to white, the green-colored MPs were identified dominantly for particle sizes $>0.5 \mathrm{~mm}$ as shown in Figures 5B,D. This may be due to some soft drink bottle plastic packaging, which are the main contributors.

Furthermore, it is suspected that the predominance of transparent MPs is due to their high susceptibility to weathering processes (Hartmann et al., 2019). This may happen due to effects of the oxidants in the digestion process, such as $\mathrm{H}_{2} \mathrm{O}_{2}$, degrading and distroying the color additives (Jiang et al., 2019). Moreover, numerous colored MPs like fibers and films, particularly with red and blue colors might lose (leach out) their color additives in the environment matrices, at the end appearing as transparent particles. Studies have reported that fishes may prey intentionally on plastic particles that possess color (e.g., transparent, white, and green) similar to their natural food items such as planktons (Nadal et al., 2016).

The proportion of transparent MPs was recorded as $37 \%$ and $33 \%$ (for particle size $<0.5 \mathrm{~mm}$ ) and $22 \%$ and $3 \%$ (for particle size $>0.5 \mathrm{~mm}$ ) in sediment and agglomerated sewage water, respectively. Therefore, the wide variety of colors for MPs infers that they might have colors resembling normal marine food, and along these lines may confuse the regular prey and predator practices and lead to color-specific ingestion by marine biota (Wright et al., 2013). Most MPs found in biota samples such as fish stomachs were normally reported as transparent colors which were not transparent during their ingestion (Selvam et al., 2021b). This means that the colored MPs taken as food were further degraded and the color additives were removed (Wright et al., 2013). Color has additionally been perceived as a decent mark of residence time for MPs on the ocean surface, and of the level of weathering (Rodríguez-Seijo and Pereira, 2016). The level of yellowing or darkening is to a great extent because of the expanded carbonyl functional group lists responsible for the degree of aging or degradation (Stolte et al., 2015). Rather than brilliant and vivid colors, MPs showed dull and faded hues, which suggests that they went through various weathering and degradation processes over a long period. This assures that the discoloration of the plastic polymer in the natural environment is an indicator of their degradation into particles (Gewert et al., 2015). Thus, it can be concluded that the diverse color identified MPs depends on the various colored source of plastic wastes and the degradation impacts on their virgincolored plastics in the environment matrices.

\section{Plastics Polymer Composition Identified MPs Polymeric Proportion}

A total of 46 representative MP particles, 19 (50\%) from agglomerated sewage water and 28 (50\%) from sediment samples, were selected for particles size $>0.5 \mathrm{~mm}$ for polymeric composition estimation. However, MPs with a particle size $<0.5 \mathrm{~mm}$ were not selected for this examination. Because examination of MPs with small particle sizes is difficult due to the unavailability of $\mu$-FTIR instruments that can map the exact polymer types. As shown in Figure 6, the identified MPs were recorded as PE, PP, PET, PS, and PVC for both sediments and agglomerated sewage water samples. The order of their MPs proportions was identified as $\mathrm{PE}=14$ (8 in agglomerated sewage water and 6 in sediment $)>P P=10$ (6 in agglomerated sewage water and 4 in sediment $)>\mathrm{PET}=6(6 \mathrm{in}$ sediment, $\approx 0$ in agglomerated sewage water) $>$ PS $=6$ (3 in agglomerated sewage water and 3 in sediment $) \approx \mathrm{PA}=6$ (4 in water, 2 in sediment $)>$ $\mathrm{PVC}=5$ ( 5 in sediment and $\approx 0$ in agglomerated sewage water). The calculated percentage proportion enumerated as with the highest of $\mathrm{PE}=30.4 \%$, followed by $\mathrm{PP}=21.74 \%$, $\mathrm{PET}=13.04 \%$, $\mathrm{PS}=13.04 \%, \mathrm{PA}=13.04 \%$, and $\mathrm{PVC}=10.87 \%$.

The high contribution of PE and PP is due to their ease of use (Lares et al., 2018; Lv et al., 2019; Magni et al., 2019), lightweight (Lares et al., 2018; Lv et al., 2019; Magni et al., 2019), and excellent mechanical futures (heat opposition, stable synthetic properties, and incredible electrical insulation) (Wen et al., 2018). Thus, these good features lead to high production of them and excessive use in commercial activities resulting in their disposal in agglomerated sewage water (Liu et al., 2019; Wagner et al., 2019), and in metropolitan stormwater runoff (Liu et al., 2019; Wagner et al., 2019). PE is highly utilized in domestic devices production, bags, and packaging materials (Kor and Mehdinia, 

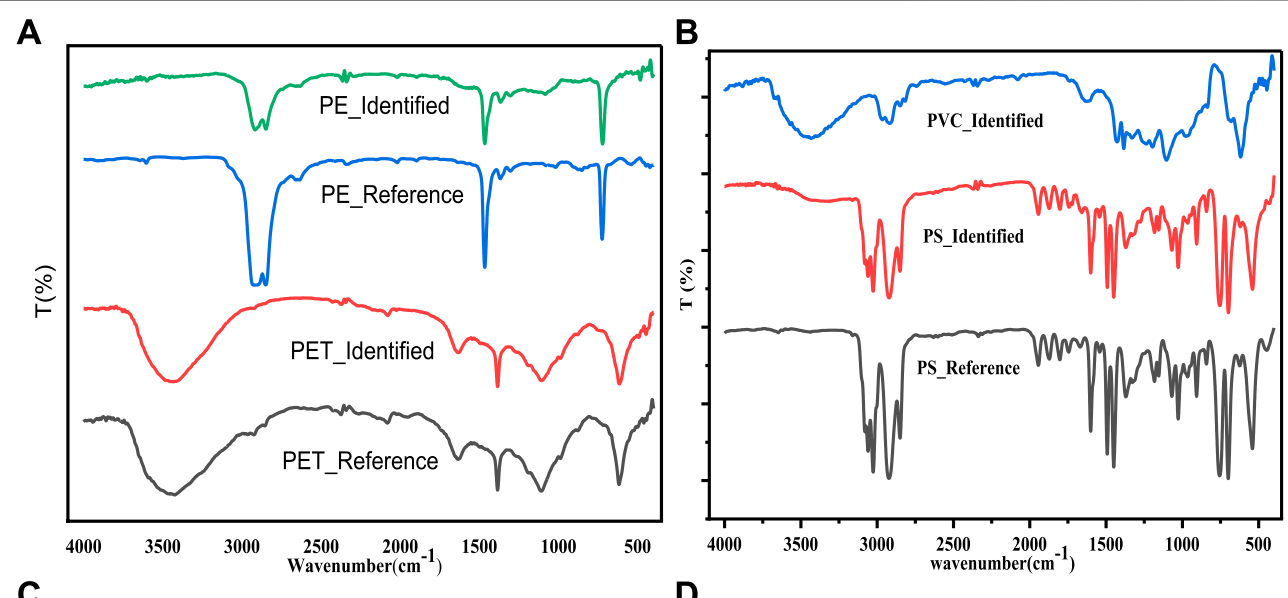

C

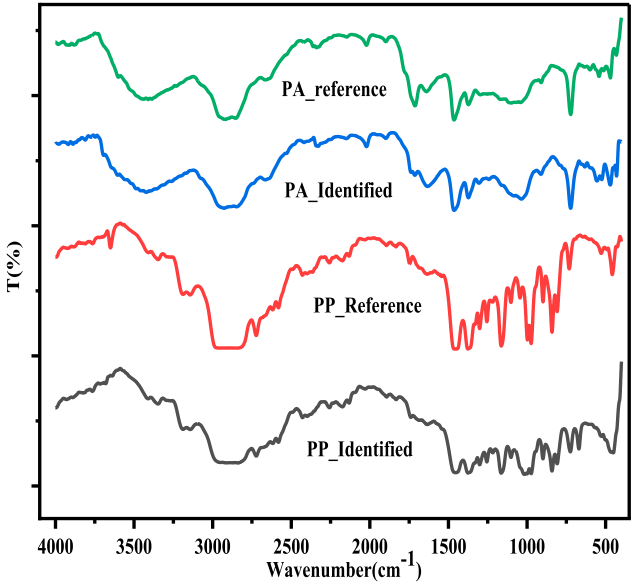

D

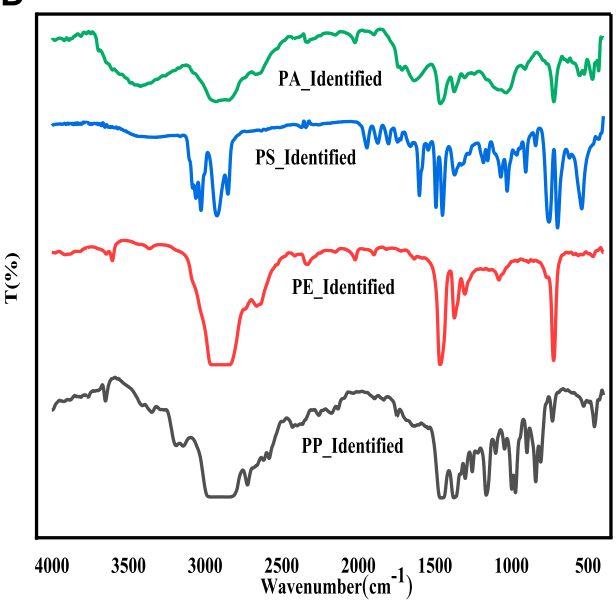

FIGURE 7 | Fourier transform infrared (FTIR) spectroscopic polymer type identification of MPs in sediment samples (A-C) and water samples (D).

2020). Due to the low-density characteristics of PP and PEderived MPs, they were recorded as a high proportion in agglomerated sewage water samples $(31.58 \%$ and $42 \%)$ than in sediments (14.3\% and 21.4\%) (Yuan et al., 2019). In the environment, biofilm formation of MP particles with associated chemicals (Selvam et al., 2021a) and microorganisms leads to a change in the density and shape of the particles resulting in them sinking to the sediment (Porter et al., 2018; Silva M. M. et al., 2019).

A good physicochemical characteristic of polystyrene (PS), such as its protection ability, durability, and being easy colorable leads for various applications such as in light ventures, shockproof materials, and beauty care products (cosmetics) results in a good proportion persisting in the natural environment (Kor and Mehdinia, 2020). Consequently, in the present study, $10.71 \%$ of sediment and $16.67 \%$ of agglomerated sewage water MP samples were identified as PS. We suspect that the private enterprises along the ditches are likely to be the possible source of those PS items. PS may be found in two principal structures: strong PS (denser than seawater) and expanded PS Foam (EPS; less dense than seawater). EPS is likely to remain in surface waters for longer periods, though the denser type of PS sinks to the sediments more quickly, which suggests that the latter can be found in agglomerated sewage water and sediment samples.

Polyamide (PA), usually known as nylon, is a polymer with high-strength fiber characteristics. PA MPs were recorded in both agglomerated sewage water and sediment samples with the proportion of $14.29 \%$ in sediment and $11.11 \%$ in agglomerated sewage water samples regardless of their density. This phenomenon demonstrates that density is not the only factor affecting the distribution of MPs. Particles with a high surface-tovolume proportion may more likely to remain suspended in water columns (Zhao et al., 2015; Lenaker et al., 2019). Sewage discharged from laundries to urban ditches and around clothmaking areas may be a significant source of nylon particles that have been used for garments and ropes (Yuan et al., 2019).

As shown in Figure 6, polyethylene terephthalate and polyvinyl chloride (PET and PVC) were exceptionally recorded only from sediment samples. They were found in the proportion of $\mathrm{PET}=21.43 \%$ and $\mathrm{PVC}=17.86 \%$. PET is generally used for various plastic containers such as water bottles (Bach et al., 2012; Nisticò, 2020). Most medical and laboratory gloves are made from PVC, which was found also in the present study. Its existence only in the sediment samples is due to its high density as it sinks to the bottom-line of the ditches (Elashmawi 
et al., 2017). PVC contains harmful additives, like dioctyl phthalate and dibutyl phthalate, possibly leaching into the environment and posing threats to human health as well as for the aquatic biotas (Capolupo et al., 2020). The types of plastic particles recorded in the present study were similar studies reported for MPs investigated from wastewater spaces in China (Zhang et al., 2017; Di and Wang, 2018). Reports suggest that the existence of MPs in the sediment samples could reflect long-term contamination for both terrestrial and aquatic environments resulting in long-term ecological pollution and impacts (Nel et al., 2018; Smith et al., 2018). The occurrence, composition, and identification of MPs in the environment are highly dependent on the sources of the plastic wastes, the techniques used (separation and identification) (Sadri and Thompson, 2014; Zhao et al., 2015). Thus, it is important to further optimize the extraction and instrumental analysis techniques.

\section{Polymer Spectral Analysis}

As shown in Figure 7, six polymer types of identified MPs particles with the corresponding standard reference plastic polymer spectra were analyzed using Fourier transform infrared spectroscopy (FTIR). The absorption peaks at $2,960-2,849 \mathrm{~cm}^{-1}, 1,471-1,450 \mathrm{~cm}^{-1}$, and $730-718 \mathrm{~cm}^{-1}$ for the $\mathrm{PE}$ particles is an assignment of the asymmetric and symmetric stretching, bending deformation, and rocking deformation of the $-\mathrm{CH}_{2}$ in the aliphatic chain, respectively (De-la-Torre et al., 2021). The standard reference plastic polymer is shown in exact peat appearance spectra. The characteristic peaks at 2,961-2,842 $\mathrm{cm}^{-1}$, $1,168 \mathrm{~cm}^{-1}, 972 \mathrm{~cm}^{-1}$, and $841 \mathrm{~cm}^{-1}$ for PP particles represent $-\mathrm{CH},-\mathrm{CH}_{3}$, and $-\mathrm{CH}_{2}$ asymmetric/symmetric stretching, $-\mathrm{CH}_{3}$ rocking, $\mathrm{C}-\mathrm{C}$ stretching, and $-\mathrm{CH}_{2}$ rocking, respectively (De-laTorre et al., 2021; De-la-Torre et al., 2022). Therefore, PE and PP items are usually buoyant due to their lower density $(0.91-0.98 \mathrm{~g} /$ $\mathrm{cm}^{3}$ ), and $\left(0.83-0.91 \mathrm{~g} / \mathrm{cm}^{3}\right)$ values (Wang et al., 2018; Zhang et al., 2020). Due to this reason, they are dominantly found in the agglomerated sewage water sample. Similarly, the standard reference plastic polymer coincides with the identified MPs. The broad absorption peaks from 3,500 to $3,415 \mathrm{~cm}^{-1}$ for PET particles and the corresponding standard reference polymers are an assignment of hydroxyl $(\mathrm{O}-\mathrm{H})$ functional groups. Also, the small peaks at around $1,645 \mathrm{~cm}^{-1}$ are attributed to the stretching vibration of carbonyl $(\mathrm{C}=\mathrm{O})$ functional groups saturated esters (Silva E. et al., 2019). Moreover, the bands at $1,386 \mathrm{~cm}^{-1}$ are associated with the asymmetric deformation in $-\mathrm{CH}_{2}$, and the bands at $1,107 \mathrm{~cm}^{-1}$ attribute with the stretching vibration of $\mathrm{C}-\mathrm{O}$ bonds. The bands at $625 \mathrm{~cm}^{-1}$ are due to the interaction vibration of $=\mathrm{C}-\mathrm{H}$ (Silva E. et al., 2019). The absorption bands at around $3,391 \mathrm{~cm}^{-1}, 2,934 \mathrm{~cm}^{-1}, 1,634 \mathrm{~cm}^{-1}, 1,466 \mathrm{~cm}^{-1}$, and $1,374 \mathrm{~cm}^{-1}$ for the PA plastic particles and the corresponding standard reference plastics exhibit the characteristic stretching vibration of amid $(\mathrm{N}-\mathrm{H})$, aliphatic $\mathrm{C}-\mathrm{H}$ stretching = $\mathrm{O}$ stretching, C-N stretching, and $\mathrm{CH}_{2}$ bending, respectively. Also, the absorptions band at $712 \mathrm{~cm}^{-1}$ interaction vibration of $\mathrm{N}-\mathrm{H}$ and $\mathrm{C}=\mathrm{O}$ bending for polyamide polymers (Zhao and Mallick, 2019). As shown in Figure 7B, the peak at $3,022 \mathrm{~cm}^{-1}$, and 2,911 and $2,844 \mathrm{~cm}^{-1}$ for the PS plastic particles were associated for each $\mathrm{CH}$ group stretching vibration to the aromatic ring, and $\mathrm{CH}$ bond stretching of $\mathrm{CH}_{2}$ groups in the aliphatic chains, respectively (Berruezo et al., 2014). A small and sharp peak of $2048 \mathrm{~cm}^{-1}$ is associated with the $\mathrm{C}=\mathrm{C}$ bond stretching in the aromatic rings. Moreover, the absorption peaks of PS around 701, 761, 1,451 , and $1,499 \mathrm{~cm}^{-1}$ correspond to the $\mathrm{C}-\mathrm{H}$ bond stretching of the aromatic rings (Berruezo et al., 2014). The characteristic peaks at $1745,1,190$, and $1,080 \mathrm{~cm}^{-1}$ are an assignment for the $\mathrm{C}=\mathrm{O}$ stretching vibration of carboxylic and ketone groups, cyclic olefin copolymer stretching vibration, and-CO-stretching vibration, respectively ( $\mathrm{Li}$ et al., 2022). The broad band around $3,450 \mathrm{~cm}^{-1}$ for the PVC plastic particles is attributed to the hydroxyl $(\mathrm{O}-\mathrm{H})$ stretching. The two adjacent small peaks at $2,975 \mathrm{~cm}^{-1}$ and $2,913 \mathrm{~cm}^{-1}$ consist of the $\mathrm{CH}_{2}$ asymmetric stretching vibration (Pandey et al., 2016). The absorption band peaks around $1,430 \mathrm{~cm}^{-1}$ correspond to the $\mathrm{C}-\mathrm{H}$ bond in deformation in the symmetric aliphatic hydrocarbon, and the broad and small peak at $1,625 \mathrm{~cm}^{-1}$ for PVC is assigned to $\mathrm{C}=\mathrm{O}$ stretching vibration (Aragaw and Mekonnen, 2021a). The C-C stretching bond of the PVC corresponds in the range $1,000-1,100 \mathrm{~cm}^{-1}$ and peaks in the range of $600-650 \mathrm{~cm}^{-1}$ $\left(616 \mathrm{~cm}^{-1}\right)$ correspond to the $\mathrm{C}-\mathrm{Cl}$ bond (Tang et al., 2018; Sobhani et al., 2019; Kitahara and Nakata, 2020). Through the absorption band analyzes carried out, several vibrations associated with specific functional groups were identified, which allowed us to identify the most likely type of polymer comprising the extracted MPs.

\section{Limitations of the Study}

Because sediment samples in the urban ditches may contain complex matrices constituents, the studied sampling sites may not be absolutely representative of the entire urban ditch system. Scaling the quantified amount of MP from the lab-scale sample size to weights in large-scale may produce sizable errors. Thus, it may require larger sample sizes (Haave et al., 2019). Since only the main ditches were considered, this may raise some uncertainties concerning Ethiopian wards (locally known as "kebele"). Even though control measures were employed for every laboratory procedure at every step in the procedure, the chance of contamination and/or losses of MPs in the sample could occur. Furthermore, undermined or overseas reading errors may arise from the visual counting and qualification of the physicochemical properties of MPs in the samples that may result from the extraction and separation chemical effects. Lastly, due to the inaccessibility of advanced analytical equipment, such as $\mu$-FTIR spectroscopy, the smallest MP fractions remained unidentified in terms of the polymeric composition.

\section{Implications of Plastic Pollution}

The study was carried out in a tourist and fishing hotspot, where extreme plastic pollution does occur as compared with other cities in the country. The present study reveals that the nearby natural water bodies (Abay River and Lake Tana) can be exposed to MPs via contaminated gateway runoffs from the urban ditches. Aragaw (2021a) reported that the highest percentage of the 
constituents in the debris survey from Lake Tana were plastics, especially single-use plastics (Aragaw, 2021a) that come from the improper disposal in urbanized areas. Also, associated toxic pollutants/chemicals, adsorbed onto MPs from clothes laundering, hotels, recreational areas, and industries can be transferred to Abay River and Lake Tana. As a result, this study focused on occurrence, identification, and quantification of MPs supports significant attempts in the light of the possibility of contamination of nearby water bodies and, thus, impact to human health via the food chain, being as Lake Tana is the main source of fish to the city hotels. Therefore, it is required to manage the plastic waste released from the city to protect the city as well the nearby water bodies. It is hoped that this study will have relevant importance in providing relevant information that is, essential to design appropriate plastic waste management systems. Conducting more detailed studies in this area is critical by providing a comprehensive investigation on the MPs pollution of a representative river that flows from the intensively affected inland waters into Lake Tana and the Blue Nile River.

\section{CONCLUSION}

The worldwide presence of plastics in the land-based and marine environment increased due to the exponential plastic production resulting in enormous consequences to ecological imbalance. Amongst all plastic drivers, rivers, which are also the mouth of urban sewage waste outflows, are highly responsible for the majority of the plastic routed into the oceans. This study was carried out to demonstrate the MP's pollution in the urban ditches (Bahir Dar) which is adjacent to Blue Nile River to conclude Bahir Dar City to be inputting plastic to the nearby water bodies. The MP pollution of urban municipalities could be determined by taking sediment and water of agglomeration samples at the urban ditches. Comparatively, the highest abundance of MPs was recorded within sediments $(5 \pm 1.00$ items $/ 50 \mathrm{~g})$ rather than the water $(3.00 \pm 1.00$ items $/ 50 \mathrm{ml})$ samples. This indicates that detected MPs particles were dominated by the high quantity of particles sinking into sediments. However, as only three sampling locations in the four main urban ditches were determined in both sediment and agglomerated sewage water samples, further detailed examination at more ditches and sampling locations is essential to draw a further conclusion.

The physicochemical characteristics of detected MPs also differed across the ditches, location, and sample types. A figure of $56.5 \%$ of the detected MPs were recorded in sediment samples, whereas $43.5 \%$ were in water samples. Out of this, $61.09 \%$ of the particles were a size of $<0.5 \mathrm{~mm}$ with the dominant shape being fragments and color being transparent; and the proportion was high in sediments compared with agglomerated sewage water samples. This may be due to frequently occuring fragmentation of plastics and sinking down to the bottom line of the ditch. The most common polymers detected in both sample types were PE and PP out of the dominant commercially used polymers (PE, PP, PET, PS, $\mathrm{PA}$, and PVC). The potential polymeric composition of MP particles was identified by FTIR. However, the misidentification rate of MPs using IR may be high. Thus, future analysis should also include more measurement of the MP particles.

As Bahir Dar City is connected to the mouth of Lake Tana and the Blue Nile River, part of the plastic wastes and their fragmented MPs will most probably be released into them an urban MP sink. Thus, further studies are required to determine the level of plastic pollution, the urban sites which are sources of entry, and the possible effects of MPs on aquatic biotas.

\section{DATA AVAILABILITY STATEMENT}

The original contributions presented in the study are included in the article/Supplementary Material, further inquiries can be directed to the corresponding author.

\section{AUTHOR CONTRIBUTIONS}

SM: Experimental Design, Investigation, Formal analysis, Writing-original draft, Data curation. TA: Supervision and Administration, Conceptualization, writing-review and editing, Validation.

\section{ACKNOWLEDGMENTS}

This paper is part of the master's thesis, for "SM," of the Environmental Engineering program under the Faculty of Chemical and Food Engineering, Bahir Dar Institute of Technology-Bahir Dar University (BiT-BDU) supervised by TA (Ph.D. candidate) for the partial fulfillment of their postgraduate studies. The authors are grateful for the financial support of the postgraduate office. Also, the authors would like to offer thanks for the laboratory chemicals, materials, and instruments support of the Chemical and Food Engineering faculty.

\section{SUPPLEMENTARY MATERIAL}

The Supplementary Material for this article can be found online at: https://www.frontiersin.org/articles/10.3389/fenvs.2022.831417/ full\#supplementary-material 


\section{REFERENCES}

Alimi, O. S., Fadare, O. O., and Okoffo, E. D. (2021). Microplastics in African Ecosystems: Current Knowledge, Abundance, Associated Contaminants, Techniques, and Research Needs. Sci. Total Environ. 755, 142422. doi:10. 1016/j.scitotenv.2020.142422

Aragaw, T. A., and Mekonnen, B. A. (2021a). Current Plastics Pollution Threats Due to COVID-19 and its Possible Mitigation Techniques: A Waste-To-Energy Conversion via Pyrolysis. Environ. Syst. Res. 10, 8. doi:10.1186/s40068-02000217-x

Aragaw, T. A., and Mekonnen, B. A. (2021b). "Distribution and Impact of Microplastics in the Aquatic Systems : A Review of Ecotoxicological Effects on Biota," in Microplastic Pollution. Sustainable Textiles: Production, Processing, Manufacturing \& Chemistry. Editor S. S. Muthu (Singapore: Springer), 65-104. doi:10.1007/978-981-16-0297-9_3

Aragaw, T. A. (2021b). Microplastic Pollution in African Countries' Water Systems: a Review on Findings, Applied Methods, Characteristics, Impacts, and Managements. SN Appl. Sci. 3, 629. doi:10.1007/s42452-021-04619-z

Aragaw, T. A. (2021a). The Macro-Debris Pollution in the Shorelines of Lake Tana: First Report on Abundance, Assessment, Constituents, and Potential Sources. Sci. Total Environ. 797, 149235. doi:10.1016/j.scitotenv.2021.149235

Auta, H. S., Emenike, C. U., and Fauziah, S. H. (2017). Distribution and Importance of Microplastics in the marine Environment: A Review of the Sources, Fate, Effects, and Potential Solutions. Environ. Int. 102, 165-176. doi:10.1016/j. envint.2017.02.013

Bach, C., Dauchy, X., Chagnon, M.-C., and Etienne, S. (2012). Chemical Compounds and Toxicological Assessments of Drinking Water Stored in Polyethylene Terephthalate (PET) Bottles: A Source of Controversy Reviewed. Water Res. 46, 571-583. doi:10.1016/j.watres.2011.11.062

Berruezo, M., Ludueña, L., Rodriguez, E., and Alvarez, V. (2014). Preparation and Characterization of Polystyrene/starch Blends for Packaging Applications. J. Plast. Film Sheeting 30, 141-161. doi:10.1177/8756087913504581

Birch, Q. T., Potter, P. M., Pinto, P. X., Dionysiou, D. D., and Al-Abed, S. R. (2020). Sources, Transport, Measurement and Impact of Nano and Microplastics in Urban Watersheds. Rev. Environ. Sci. Biotechnol. 19, 275-336. doi:10.1007/ s11157-020-09529-x

Botterell, Z. L. R., Beaumont, N., Dorrington, T., Steinke, M., Thompson, R. C., and Lindeque, P. K. (2019). Bioavailability and Effects of Microplastics on Marine Zooplankton: A Review. Environ. Pollut. 245, 98-110. doi:10.1016/j.envpol. 2018.10.065

Campos da Rocha, F. O., Martinez, S. T., Campos, V. P., da Rocha, G. O., and de Andrade, J. B. (2021). Microplastic Pollution in Southern Atlantic marine Waters: Review of Current Trends, Sources, and Perspectives. Sci. Total Environ. 782, 146541. doi:10.1016/j.scitotenv.2021.146541

Capolupo, M., Sørensen, L., Jayasena, K. D. R., Booth, A. M., and Fabbri, E. (2020). Chemical Composition and Ecotoxicity of Plastic and Car Tire Rubber Leachates to Aquatic Organisms. Water Res. 169, 115270. doi:10.1016/j. watres.2019.115270

Carpenter, E. J., Anderson, S. J., Harvey, G. R., Miklas, H. P., and Peck, B. B. (1972). Polystyrene Spherules in Coastal Waters. Science 178, 749-750. doi:10.1126/ science.178.4062.749

Carpenter, E. J., and Smith, K. L. (1972). Plastics on the Sargasso Sea Surface. Science 175, 1240-1241. doi:10.1126/science.175.4027.1240

Chaukura, N., Kefeni, K. K., Chikurunhe, I., Nyambiya, I., Gwenzi, W., Moyo, W., et al. (2021). Microplastics in the Aquatic Environment-The Occurrence, Sources, Ecological Impacts, Fate, and Remediation Challenges. Pollutants 1, 95-118. doi:10.3390/pollutants1020009

Cole, M., Lindeque, P., Halsband, C., and Galloway, T. S. (2011). Microplastics as Contaminants in the marine Environment: a Review. Mar. Pollut. Bull. 62, 2588-2597. doi:10.1016/j.marpolbul.2011.09.025

De Falco, F., Di Pace, E., Cocca, M., and Avella, M. (2019). The Contribution of Washing Processes of Synthetic Clothes to Microplastic Pollution. Sci. Rep. 9, 1-11. doi:10.1038/s41598-019-43023-x

De-la-Torre, G. E., Dioses-Salinas, D. C., Pérez-Baca, B. L., Millones Cumpa, L. A., Pizarro-Ortega, C. I., Torres, F. G., et al. (2021). Marine Macroinvertebrates Inhabiting Plastic Litter in Peru. Mar. Pollut. Bull. 167, 112296. doi:10.1016/j. marpolbul.2021.112296
De-la-Torre, G. E., Dioses-Salinas, D. C., Pizarro-Ortega, C. I., Fernández Severini, M. D., Forero López, A. D., Mansilla, R., et al. (2022). Binational Survey of Personal Protective Equipment (PPE) Pollution Driven by the COVID-19 Pandemic in Coastal Environments: Abundance, Distribution, and Analytical Characterization. J. Hazard. Mater. 426, 128070. doi:10.1016/j. jhazmat.2021.128070

Desforges, J.-P. W., Galbraith, M., Dangerfield, N., and Ross, P. S. (2014). Widespread Distribution of Microplastics in Subsurface Seawater in the NE Pacific Ocean. Mar. Pollut. Bull. 79, 94-99. doi:10.1016/j.marpolbul.2013. 12.035

Devriese, L. I., De Witte, B., Vethaak, A. D., Hostens, K., and Leslie, H. A. (2017) Bioaccumulation of PCBs from Microplastics in Norway Lobster (Nephrops N): An Experimental Study. Chemosphere 186, 10-16. doi:10.1016/j.chemosphere. 2017.07.121

Di, M., and Wang, J. (2018). Microplastics in Surface Waters and Sediments of the Three Gorges Reservoir, China. Sci. Total Environ. 616-617, 1620-1627. doi:10. 1016/j.scitotenv.2017.10.150

Ding, J., Jiang, F., Li, J., Wang, Z., Sun, C., Wang, Z., et al. (2019). Microplastics in the Coral Reef Systems from Xisha Islands of South China Sea. Environ. Sci. Technol. 53, 8036-8046. doi:10.1021/acs.est.9b01452

Elashmawi, I. S., Alatawi, N. S., and Elsayed, N. H. (2017). Preparation and Characterization of Polymer Nanocomposites Based on PVDF/PVC Doped with Graphene Nanoparticles. Results Phys. 7, 636-640. doi:10.1016/j.rinp. 2017.01.022

Espiritu, E. Q., Dayrit, S. A. S., Coronel, A. S. O., Paz, N. S. C., Ronquillo, P. I. L., Castillo, V. C. G., et al. (2019). Assessment of Quantity and Quality of Microplastics in the Sediments, Waters, Oysters, and Selected Fish Species in Key Sites along the Bombong Estuary and the Coastal Waters of Ticalan in San Juan, Batangas. Philipp. J. Sci. 148, 789-816.

Fenta, B. A. (2017). Waste Management in the Case of Bahir Dar City Near Lake Tana Shore in Northwestern Ethiopia. Afr. J. Environ. Sci. Technol. 11, 393-412. doi:10.5897/AJEST2017.2340

Galgani, F., Hanke, G., Werner, S., and De Vrees, L. (2013). Marine Litter within the European Marine Strategy Framework Directive. ICES J. Mar. Sci. 70, 1055-1064. doi:10.1093/icesjms/fst122

Gewert, B., Plassmann, M. M., and Macleod, M. (2015). Pathways for Degradation of Plastic Polymers Floating in the Marine Environment. Environ. Sci. Process. Impacts 17, 1513-1521. doi:10.1039/c5em00207a

Gies, E. A., LeNoble, J. L., Noël, M., Etemadifar, A., Bishay, F., Hall, E. R., et al. (2018). Retention of Microplastics in a Major Secondary Wastewater Treatment Plant in Vancouver, Canada. Mar. Pollut. Bull. 133, 553-561. doi:10.1016/j. marpolbul.2018.06.006

Haave, M., Lorenz, C., Primpke, S., and Gerdts, G. (2019). Different Stories Told by Small and Large Microplastics in Sediment - First Report of Microplastic Concentrations in an Urban Recipient in Norway. Mar. Pollut. Bull. 141, 501-513. doi:10.1016/j.marpolbul.2019.02.015

Hartmann, N. B., Hüffer, T., Thompson, R. C., Hassellöv, M., Verschoor, A., Daugaard, A. E., et al. (2019). Are We Speaking the Same Language? Recommendations for a Definition and Categorization Framework for Plastic Debris. Environ. Sci. Technol. 53, 1039-1047. doi:10.1021/acs.est. 8 b05297

Hazimah, N., Nor, M., and Obbard, J. P. (2014). Microplastics in Singapore's Coastal Mangrove Ecosystems. Mar. Pollut. Bull. 79, 278-283. doi:10.1016/j. marpolbul.2013.11.025

Henry, B., Laitala, K., and Klepp, I. G. (2019). Microfibres from Apparel and Home Textiles: Prospects for Including Microplastics in Environmental Sustainability Assessment. Sci. Total Environ. 652, 483-494. doi:10.1016/j.scitotenv.2018. 10.166

Hernandez, E., Nowack, B., and Mitrano, D. M. (2017). Polyester Textiles as a Source of Microplastics from Households: A Mechanistic Study to Understand Microfiber Release during Washing. Environ. Sci. Technol. 51, 7036-7046. doi:10.1021/acs.est.7b01750

Huppertsberg, S., and Knepper, T. P. (2018). Instrumental Analysis of Microplastics-Benefits and Challenges. Anal. Bioanal. Chem. 410, 6343-6352. doi:10.1007/s00216-018-1210-8

Ivar, J. A., and Costa, M. F. (2014). The Present and Future of Microplastic Pollution in the Marine Environment. Environ. Pollut. 185, 352-364. doi:10. 1016/j.envpol.2013.10.036 
Jian, M. F., Zhou, L. Y., Yu, H. P., and Liu, S. (2018). Separation and Microscopic Study of Microplastics from the Sediments of the Wetland in the Estuary of Raohe River of Poyang Lake. Acta Sci. Circumstantiae 38, 579-586. doi:10. 13671/j.hjkxxb.2017.0369

Jiang, C., Yin, L., Li, Z., Wen, X., Luo, X., Hu, S., et al. (2019). Microplastic Pollution in the Rivers of the Tibet Plateau. Environ. Pollut. 249, 91-98. doi:10.1016/j. envpol.2019.03.022

Jiang, C., Yin, L., Wen, X., Du, C., Wu, L., Long, Y., et al. (2018). Microplastics in Sediment and Surface Water of West Dongting lake and South Dongting lake: Abundance, Source and Composition. Int. J. Environ. Res. Public Health 15, 2164. doi:10.3390/ijerph15102164

Kitahara, K.-I., and Nakata, H. (2020). Plastic Additives as Tracers of Microplastic Sources in Japanese Road Dusts. Sci. Total Environ. 736, 139694. doi:10.1016/j. scitotenv.2020.139694

Klein, S., Worch, E., and Knepper, T. P. (2015). Occurrence and Spatial Distribution of Microplastics in River Shore Sediments of the Rhine-Main Area in Germany. Environ. Sci. Technol. 49, 6070-6076. doi:10.1021/acs.est. $5 b 00492$

Kor, K., and Mehdinia, A. (2020). Neustonic Microplastic Pollution in the Persian Gulf. Mar. Pollut. Bull. 150, 110665. doi:10.1016/j.marpolbul.2019.110665

Lares, M., Ncibi, M. C., Sillanpää, M., and Sillanpää, M. (2018). Occurrence, Identification and Removal of Microplastic Particles and Fibers in Conventional Activated Sludge Process and Advanced MBR Technology. Water Res. 133, 236-246. doi:10.1016/j.watres.2018.01.049

Lebreton, L. C. M., Van Der Zwet, J., Damsteeg, J.-W., Slat, B., Andrady, A., and Reisser, J. (2017). River Plastic Emissions to the World's Oceans. Nat. Commun. 8, 15611. doi:10.1038/ncomms15611

Lenaker, P. L., Baldwin, A. K., Corsi, S. R., Mason, S. A., Reneau, P. C., and Scott, J. W. (2019). Vertical Distribution of Microplastics in the Water Column and Surficial Sediment from the Milwaukee River Basin to Lake Michigan. Environ. Sci. Technol. 53, 12227-12237. doi:10.1021/acs.est.9b03850

Leslie, H. A., Brandsma, S. H., van Velzen, M. J. M., and Vethaak, A. D. (2017). Microplastics en Route: Field Measurements in the Dutch River Delta and Amsterdam Canals, Wastewater Treatment Plants, North Sea Sediments and Biota. Environ. Int. 101, 133-142. doi:10.1016/j.envint.2017.01.018

Li, X., Chen, L., Mei, Q., Dong, B., Dai, X., Ding, G., et al. (2018). Microplastics in Sewage Sludge from the Wastewater Treatment Plants in China. Water Res. 142, 75-85. doi:10.1016/j.watres.2018.05.034

Li, Y., Li, J., Ding, J., Song, Z., Yang, B., Zhang, C., et al. (2022). Degradation of NanoSized Polystyrene Plastics by Ozonation or Chlorination in Drinking Water Disinfection Processes. Chem. Eng. J. 427, 131690. doi:10.1016/j.cej.2021.131690

Liu, F., Olesen, K. B., Borregaard, A. R., and Vollertsen, J. (2019). Microplastics in Urban and Highway Stormwater Retention Ponds. Sci. Total Environ. 671, 992-1000. doi:10.1016/j.scitotenv.2019.03.416

Lv, X., Dong, Q., Zuo, Z., Liu, Y., Huang, X., and Wu, W.-M. (2019). Microplastics in a Municipal Wastewater Treatment Plant: Fate, Dynamic Distribution, Removal Efficiencies, and Control Strategies. J. Clean. Prod. 225, 579-586. doi:10.1016/j.jclepro.2019.03.321

Magni, S., Binelli, A., Pittura, L., Avio, C. G., Della Torre, C., Parenti, C. C., et al. (2019). The Fate of Microplastics in an Italian Wastewater Treatment Plant. Sci. Total Environ. 652, 602-610. doi:10.1016/j.scitotenv.2018.10.269

Masura, J., Baker, J., Foster, G., and Arthur, C. (2015). Laboratory Methods for the Analysis of Microplastics in the Marine Environment: Recommendations for Quantifying Synthetic Particles in Waters and Sediments. NOAA Technical Memorandum NOS-OR and R-48, 1-39.

Merga, L. B., Redondo-Hasselerharm, P. E., Van den Brink, P. J., and Koelmans, A. A. (2020). Distribution of Microplastic and Small Macroplastic Particles across Four Fish Species and Sediment in an African Lake. Sci. Total Environ. 741, 140527. doi:10.1016/j.scitotenv.2020.140527

Nadal, M. A., Alomar, C., and Deudero, S. (2016). High Levels of Microplastic Ingestion by the Semipelagic Fish Bogue Boops B (L.) Around the Balearic Islands. Environ. Pollut. 214, 517-523. doi:10.1016/j.envpol.2016.04.054

Napper, I. E., Bakir, A., Rowland, S. J., and Thompson, R. C. (2015). Characterisation, Quantity and Sorptive Properties of Microplastics Extracted from Cosmetics. Mar. Pollut. Bull. 99, 178-185. doi:10.1016/j. marpolbul.2015.07.029

Nel, H. A., Dalu, T., and Wasserman, R. J. (2018). Sinks and Sources: Assessing Microplastic Abundance in River Sediment and deposit Feeders in an Austral
Temperate Urban River System. Sci. Total Environ. 612, 950-956. doi:10.1016/j. scitotenv.2017.08.298

Nisticò, R. (2020). Polyethylene Terephthalate (PET) in the Packaging Industry. Polym. Test. 90, 106707. doi:10.1016/j.polymertesting.2020.106707

Pandey, M., Joshi, G. M., Mukherjee, A., and Thomas, P. (2016). Electrical Properties and Thermal Degradation of Poly(Vinyl Chloride)/Polyvinylidene Fluoride/ZnO Polymer Nanocomposites. Polym. Int. 65, 1098-1106. doi:10. $1002 /$ pi.5161

Peng, G., Xu, P., Zhu, B., Bai, M., and Li, D. (2018). Microplastics in Freshwater River Sediments in Shanghai, China: A Case Study of Risk Assessment in MegaCities. Environ. Pollut. 234, 448-456. doi:10.1016/j.envpol.2017.11.034

PlasticsEurope (2019). An Analysis of European Plastics Production, Demand and Waste Data. PlasticsEurope: Düsseldorf.

Porter, A., Lyons, B. P., Galloway, T. S., and Lewis, C. (2018). Role of Marine Snows in Microplastic Fate and Bioavailability. Environ. Sci. Technol. 52, 7111-7119. doi:10.1021/acs.est.8b01000

Prata, J. C., da Costa, J. P., Duarte, A. C., and Rocha-Santos, T. (2019). Methods for Sampling and Detection of Microplastics in Water and Sediment: A Critical Review. Trac Trends Anal. Chem. 110, 150-159. doi:10.1016/j.trac.2018.10.029

Qi, H., Fu, D., Wang, Z., Gao, M., and Peng, L. (2020). Microplastics Occurrence and Spatial Distribution in Seawater and Sediment of Haikou Bay in the Northern South China Sea. Estuarine, Coastal Shelf Sci. 239, 106757. doi:10. 1016/j.ecss.2020.106757

Rodríguez-Seijo, A., and Pereira, R. (2016). Chapter 3: Morphological and Physical Characterization of Microplastics. Compr. Anal. Chem. 75, 49-65. doi:10.1016/ bs.coac.2016.10.007

Sadri, S. S., and Thompson, R. C. (2014). On the Quantity and Composition of Floating Plastic Debris Entering and Leaving the Tamar Estuary, Southwest England. Mar. Pollut. Bull. 81, 55-60. doi:10.1016/j.marpolbul.2014.02.020

Schnurr, R. E. J., Alboiu, V., Chaudhary, M., Corbett, R. A., Quanz, M. E., Sankar, K., et al. (2018). Reducing Marine Pollution from Single-Use Plastics (SUPs): A Review. Mar. Pollut. Bull. 137, 157-171. doi:10.1016/j.marpolbul.2018.10.001

Selvam, S., Jesuraja, K., Venkatramanan, S., Roy, P. D., and Jeyanthi Kumari, V. (2021a). Hazardous Microplastic Characteristics and its Role as a Vector of Heavy Metal in Groundwater and Surface Water of Coastal South India. J. Hazard. Mater. 402, 123786. doi:10.1016/j.jhazmat.2020.123786

Selvam, S., Manisha, A., Roy, P. D., Venkatramanan, S., Chung, S. Y., Muthukumar, P., et al. (2021b). Microplastics and Trace Metals in Fish Species of the Gulf of Mannar (Indian Ocean) and Evaluation of Human Health. Environ. Pollut. 291, 118089. doi:10.1016/j.envpol.2021.118089

Shahul Hamid, F., Bhatti, M. S., Anuar, N., Anuar, N., Mohan, P., and Periathamby, A. (2018). Worldwide Distribution and Abundance of Microplastic: How Dire Is the Situation? Waste Manag. Res. 36, 873-897. doi:10.1177/0734242X18785730

Silva, E., Fedel, M., Deflorian, F., Cotting, F., and Lins, V. (2019a). Properties of Post-Consumer Polyethylene Terephthalate Coating Mechanically Deposited on Mild Steels. Coatings 9, 28. doi:10.3390/coatings9010028

Silva, M. M., Maldonado, G. C., Castro, R. O., de Sá Felizardo, J., Cardoso, R. P., Anjos, R. M. D., et al. (2019b). Dispersal of Potentially Pathogenic Bacteria by Plastic Debris in Guanabara Bay, RJ, Brazil. Mar. Pollut. Bull. 141, 561-568. doi:10.1016/j.marpolbul.2019.02.064

Smith, S. D. A., Banister, K., Fraser, N., and Edgar, R. J. (2018). Tracing the Source of marine Debris on the Beaches of Northern New South Wales, Australia: The Bottles on Beaches Program. Mar. Pollut. Bull. 126, 304-307. doi:10.1016/j. marpolbul.2017.11.022

Sobhani, Z., Al Amin, M., Naidu, R., Megharaj, M., and Fang, C. (2019). Identification and Visualisation of Microplastics by Raman Mapping. Analytica Chim. Acta 1077, 191-199. doi:10.1016/j.aca.2019.05.021

Song, Y. K., Hong, S. H., Jang, M., Han, G. M., Jung, S. W., and Shim, W. J. (2017). Combined Effects of UV Exposure Duration and Mechanical Abrasion on Microplastic Fragmentation by Polymer Type. Environ. Sci. Technol. 51, 4368-4376. doi:10.1021/acs.est.6b06155

Stolte, A., Forster, S., Gerdts, G., and Schubert, H. (2015). Microplastic Concentrations in Beach Sediments along the German Baltic Coast. Mar. Pollut. Bull. 99, 216-229. doi:10.1016/j.marpolbul.2015.07.022

Tang, C.-C., Chen, H.-I., Brimblecombe, P., and Lee, C.-L. (2018). Textural, Surface and Chemical Properties of Polyvinyl Chloride Particles Degraded in a Simulated Environment. Mar. Pollut. Bull. 133, 392-401. doi:10.1016/j. marpolbul.2018.05.062 
Tassie, K., and Endalew, B. (2020). Willingness to Pay for Improved Solid Waste Management Services and Associated Factors Among Urban Households: One and One Half Bounded Contingent Valuation Study in Bahir Dar City, Ethiopia. Cogent Environ. Sci. 6, 1807275. doi:10.1080/23311843.2020.1807275

Teuten, E. L., Rowland, S. J., Galloway, T. S., and Thompson, R. C. (2007). Potential for Plastics to Transport Hydrophobic Contaminants. Environ. Sci. Technol. 41 (22), 7759-7764. doi:10.1021/es071737s

Tibbetts, J., Krause, S., Lynch, I., and Sambrook Smith, G. (2018). Abundance, Distribution, and Drivers of Microplastic Contamination in Urban River Environments. Water 10, 1597. doi:10.3390/w10111597

Triebskorn, R., Braunbeck, T., Grummt, T., Hanslik, L., Huppertsberg, S., Jekel, M., et al. (2019). Relevance of Nano- and Microplastics for Freshwater Ecosystems: A Critical Review. Trac Trends Anal. Chem. 110, 375-392. doi:10.1016/j.trac.2018.11.023

Turner, A. (2018). Black Plastics: Linear and Circular Economies, Hazardous Additives and Marine Pollution. Environ. Int. 117, 308-318. doi:10.1016/j. envint.2018.04.036

Veerasingam, S., Ranjani, M., Venkatachalapathy, R., Bagaev, A., Mukhanov, V., Litvinyuk, D., et al. (2020). Contributions of Fourier Transform Infrared Spectroscopy in Microplastic Pollution Research: A Review. Crit. Rev. Environ. Sci. Technol. 51, 2681-2743. doi:10.1080/10643389.2020.1807450

Wagner, M., and Lambert, S. (2018). "Microplastics Are Contaminants of Emerging Concern in Freshwater Environments: An Overview," in Freshwater Microplastics. Editors M. Wagner and S. Lambert (Cham, Switzerland: Springer Science and Business Media LLC), 1-23. doi:10.1007/ 978-3-319-61615-5

Wagner, S., Klöckner, P., Stier, B., Römer, M., Seiwert, B., Reemtsma, T., et al. (2019). Relationship between Discharge and River Plastic Concentrations in a Rural and an Urban Catchment. Environ. Sci. Technol. 53, 10082-10091. doi:10. 1021/acs.est.9b03048

Wang, W., Yuan, W., Chen, Y., and Wang, J. (2018). Microplastics in Surface Waters of Dongting Lake and Hong Lake, China. Sci. Total Environ. 633, 539-545. doi:10.1016/j.scitotenv.2018.03.211

Wen, X., Du, C., Xu, P., Zeng, G., Huang, D., Yin, L., et al. (2018). Microplastic Pollution in Surface Sediments of Urban Water Areas in Changsha, China: Abundance, Composition, Surface Textures. Mar. Pollut. Bull. 136, 414-423. doi:10.1016/j.marpolbul.2018.09.043

Werbowski, L. M., Gilbreath, A. N., Munno, K., Zhu, X., Grbic, J., Wu, T., et al. (2021). Urban Stormwater Runoff: A Major Pathway for Anthropogenic Particles, Black Rubbery Fragments, and Other Types of Microplastics to Urban Receiving Waters. ACS EST Water 1, 1420-1428. doi:10.1021/ acsestwater.1c00017

Willis, K. A., Eriksen, R., Wilcox, C., and Hardesty, B. D. (2017). Microplastic Distribution at Different Sediment Depths in an Urban Estuary. Front. Mar. Sci. 4, 1-8. doi:10.3389/fmars.2017.00419

Wright, S. L., Thompson, R. C., and Galloway, T. S. (2013). The Physical Impacts of Microplastics on marine Organisms: A Review. Environ. Pollut. 178, 483-492. doi:10.1016/j.envpol.2013.02.031

Xiong, X., Zhang, K., Chen, X., Shi, H., Luo, Z., and Wu, C. (2018). Sources and Distribution of Microplastics in China's Largest Inland Lake - Qinghai Lake. Environ. Pollut. 235, 899-906. doi:10.1016/j.envpol.2017.12.081

Xu, J.-L., Thomas, K. V., Luo, Z., and Gowen, A. A. (2019). FTIR and Raman Imaging for Microplastics Analysis: State of the Art, Challenges and Prospects. Trac Trends Anal. Chem. 119, 115629. doi:10.1016/j.trac.2019.115629
Yuan, W., Liu, X., Wang, W., Di, M., and Wang, J. (2019). Microplastic Abundance, Distribution and Composition in Water, Sediments, and Wild Fish from Poyang Lake, China. Ecotoxicology Environ. Saf. 170, 180-187. doi:10.1016/j. ecoenv.2018.11.126

Zbyszewski, M., Corcoran, P. L., and Hockin, A. (2014). Comparison of the Distribution and Degradation of Plastic Debris along Shorelines of the Great Lakes, North America. J. Great Lakes Res. 40, 288-299. doi:10.1016/j. jglr.2014.02.012

Zhang, D., Cui, Y., Zhou, H., Jin, C., Yu, X., Xu, Y., et al. (2020). Microplastic Pollution in Water, Sediment, and Fish from Artificial Reefs Around the Ma'an Archipelago, Shengsi, China. Sci. Total Environ. 703, 134768. doi:10.1016/j. scitotenv.2019.134768

Zhang, K., Shi, H., Peng, J., Wang, Y., Xiong, X., Wu, C., et al. (2018). Microplastic Pollution in China's Inland Water Systems: A Review of Findings, Methods, Characteristics, Effects, and Management. Sci. Total Environ. 630, 1641-1653. doi:10.1016/j.scitotenv.2018.02.300

Zhang, K., Xiong, X., Hu, H., Wu, C., Bi, Y., Wu, Y., et al. (2017). Occurrence and Characteristics of Microplastic Pollution in Xiangxi Bay of Three Gorges Reservoir, China. Environ. Sci. Technol. 51, 3794-3801. doi:10.1021/acs.est. $7 \mathrm{~b} 00369$

Zhao, J., and Mallick, P. K. (2019). Effect of Biodiesel on Polyamide-6-Based Polymers. Polym. Eng. Sci. 59, 1445-1454. doi:10.1002/pen.25131

Zhao, S., Zhu, L., and Li, D. (2015). Microplastic in Three Urban Estuaries, China. Environ. Pollut. 206, 597-604. doi:10.1016/j.envpol.2015.08.027

Zhao, W., Huang, W., Yin, M., Huang, P., Ding, Y., Ni, X., et al. (2020). Tributary Inflows Enhance the Microplastic Load in the Estuary: A Case from the Qiantang River. Mar. Pollut. Bull. 156, 111152. doi:10.1016/j.marpolbul. 2020.111152

Zheng, Y., Li, J., Cao, W., Liu, X., Jiang, F., Ding, J., et al. (2019). Distribution Characteristics of Microplastics in the Seawater and Sediment: A Case Study in Jiaozhou Bay, China. Sci. Total Environ. 674, 27-35. doi:10.1016/j.scitotenv. 2019.04.008

Zobkov, M. B., and Esiukova, E. E. (2018). Microplastics in a Marine Environment: Review of Methods for Sampling, Processing, and Analyzing Microplastics in Water, Bottom Sediments, and Coastal Deposits. Oceanology 58, 137-143. doi:10.1134/S0001437017060169

Conflict of Interest: The authors declare that the research was conducted in the absence of any commercial or financial relationships that could be construed as a potential conflict of interest.

Publisher's Note: All claims expressed in this article are solely those of the authors and do not necessarily represent those of their affiliated organizations, or those of the publisher, the editors and the reviewers. Any product that may be evaluated in this article, or claim that may be made by its manufacturer, is not guaranteed or endorsed by the publisher.

Copyright $(2022$ Mhiret Gela and Aragaw. This is an open-access article distributed under the terms of the Creative Commons Attribution License (CC BY). The use, distribution or reproduction in other forums is permitted, provided the original author(s) and the copyright owner(s) are credited and that the original publication in this journal is cited, in accordance with accepted academic practice. No use, distribution or reproduction is permitted which does not comply with these terms. 